\title{
News Shocks and Business Cycles: Evidence from Forecast Data*
}

\author{
Wataru Miyamoto and Thuy Lan Nguyen \\ Columbia University
}

First version: January 2012

This version: February 7, 2014

\begin{abstract}
This paper proposes the use of data on expectations to identify the role of news shocks in business cycles. This approach exploits the fact that news shocks cause agents to adjust their expectations about the future even when current fundamentals are not affected, therefore, data on expectations are particularly informative about the role of news shocks. Using data on expectations, we estimate a dynamic, stochastic, general equilibrium model that incorporates news shocks for the U.S. between 1955Q1 and 2006Q4. We find that the contribution of news shocks to output is about half of that estimated without data on expectations. The precision of the estimated role of news shocks also greatly improves when data on expectations are used. Moreover, the contribution of news shocks to explaining short run fluctuations is negligible. These results arise because data on expectations show that changes in expectations are not large and do not resemble actual movements of output. Therefore, news shocks cannot be the main driver of business cycles.
\end{abstract}

JEL classification: C11, E12, E13, E32

Keywords: news, anticipated shocks, perfect information, DSGE model, Bayesian methods, expectation

${ }^{*}$ We thank Emi Nakamura, Stephanie Schmitt-Grohé, Jón Steinsson, Martín Uribe for their constant support and advices. We have also benefited from various comments by Jonathan Dingel, Tommaso Monacelli, Jaromir Nosal, Ricardo Reis, and Michael Woodford. We also thank participants at the Columbia Economic Fluctuation Colloquium for their comments. Correspondence: wm2218@columbia.edu and tn2208@columbia.edu 


\section{Introduction}

A large recent literature starting from Beaudry and Portier (2006) has focused on news shocks as the main driver of business cycles. News shocks in this literature are defined as information about future fundamentals that does not affect current fundamentals. When agents learn that there will be changes in exogenous fundamentals in the future, they change their current behavior, causing economic fluctuations which in turn are observed in realized data. Therefore, the literature on news shocks has used traditional macroeconomic realized data such as output and consumption to infer news shocks. However, since news shocks can only affect current outcomes through expectations, data on expectations should be useful in understanding the role of news shocks.

To illustrate how data on expectations can be informative about the role of news shocks, we show that news shocks can have strong implications about the movements of expectations in the model, which are different from the data. Figure 1 plots the realized output growth rate of the US between 1970Q1 and 2006Q4 along with the model-implied expectations of output in Schmitt-Grohé and Uribe (2012). Estimated with only realized data, the model implies that news explains about half of the fluctuations in output. As a result, there are large changes in expectations that resemble the movements of realized output. However, these movements of the model-implied expectations are significantly different from those of data on expectations, which are also plotted in Figure 1. First, while the model-implied expectations track the movements of realized output fairly well, data on expectations do not. For example, in the model, agents could anticipate a year in advance that output would decline in 2001. However, data on expectations suggest that agents actually expected a boom. The differences between the model-implied expectations and data on expectations are also clear in other instances such as the 1981-82 recession. Second, data on expectations are generally smoother than the model-implied expectation; especially after 1985, there are no drastic movements in data on expectations in contrast to the more substantial changes in the model-implied expectations.

Motivated by these observations, this paper uses data on expectations to quantify the role of news shocks in business cycles. More specifically, we estimate a standard real dynamic stochastic general equilibrium model with Bayesian methods using both realized data and data on expectations. We use forecast data from the Survey of Professional Forecasters to measure expectations of agents in the economy and match them with the expectations of the agents in the model.

Our estimation shows that adding data on expectation changes the inference about news shocks significantly. We find that news shocks explains about $24 \%$ of the aggregate fluctuations in output 
when the estimation includes data on expectations. This estimate is about half of the estimated contribution of news shocks without data on expectations. Furthermore, this result is robust across a range of model specifications including models with and without nominal rigidities.

Another important finding of our paper is that the precision of the estimates greatly improves when using data on expectations, suggesting that data on expectations are useful in inferring news shocks. Without data on expectations, the contribution of news shocks to aggregate variables is imprecise. For example, for the volatilities of government spending, the $95 \%$ confidence interval is between $10 \%$ and $90 \%$. In contrast, with data on expectations, this interval narrows to between $2 \%$ and $18 \%$.

The reason for the smaller estimated contribution of news shocks and the substantial increase in precision is that data on expectations restrict the role of news shocks in driving business cycle fluctuations. In response to news shocks, the economy responds slowly until the shock materializes. Since agents know that the shock will materialize, agents can expect that the largest response of output growth will be when actual changes in fundamentals materialize. In other words, their expectations about future output growth rate will move. When we observe data on expectations, we put a restriction on how large the movements of expectations in the model can be. As data on expectations are generally smooth and do not resemble realized output much, the estimation with data on expectations attributes a smaller role to news shocks than the estimation without data on expectations. This restriction is especially helpful in identifying the types of news shocks that do not create significant "Pigou cycles", which are aggregate fluctuations caused by changes in expectations when shocks have not materialized yet. In other words, with these types of news shocks, whether agents know that the shock will happen in advance or not does not matter for their current behavior. Without data on expectations, it is difficult to distinguish this type of news shocks from an unanticipated shock of the same kind. Therefore, estimation results without data on expectations can be driven by priors. By observing how expectations move in the data, we can separate unanticipated shocks that change output immediately without changing expectations from news shocks that only change expectations, which leads to a much more precise estimate of news shocks.

Although news shocks account for about $24 \%$ of output fluctuations in the long run, news shocks are negligible in explaining the short run fluctuations before actual changes in fundamentals happen. In the model, there are two types of news shocks: those that create Pigou cycles and those that do not. News shocks that do not create Pigou cycles cannot generate substantial fluctuations in the short 
run. News shocks that generate Pigou cycles can potentially cause significant short run fluctuations. However, the role of these news shocks is quantitatively modest. Therefore, news shocks are not important in explaining short run fluctuations before the shock materializes, i.e. for horizons up to two years. Only $10 \%$ of the fluctuations of output and $7 \%$ of the fluctuations of hours within two years are explained by news shocks. The rest of the macroeconomic variations are accounted for by unanticipated shocks.

Among different types of news shocks considered, news about demand shocks is close to zero. For instance, news about preference shocks explain less than $1 \%$ of the variations of output and only $5 \%$ of the fluctuations of consumption, and news about government spending shocks explain less than $6 \%$ of the government spending variations. The reason for such a small contribution of news about demand shocks is because they do not generate substantial Pigou cycles. When agents receive news that there will be a positive preference shock in the future, they expect that future output will increase, but their current behaviors do not change significantly. Therefore, if news about demand shocks were important, we would observe that expectations of output fluctuate strongly with little change in current output. However, data on expectations do not exhibit large movements over time. Therefore, the role of news about demand shocks is negligible.

In terms of historical episodes, we find that news shocks are important in explaining the 1980 recession and the 1993-94 episodes but do not explain much of other business cycles in our sample, consistent with data on expectations. In the case of 1980 recession, data on expectations show that agents had information about the consequences of an oil price increase a year in advance with the Iranian war going on. Therefore, agents expected that output would decline, and output actually declined as expected. However, for other business cycles in the sample, agents did not have much information about future output movements until they actually observed the shocks and updated their expectations, resulting in news being unimportant.

Additionally, we show that our above results are robust across model specifications, further suggesting the usefulness of data on expectations in inferring news shocks. In a version of our model with nominal rigidities, news shocks explain $28 \%$ of output fluctuations, similar to the $24 \%$ estimated in the baseline model without nominal rigidities. This result is consistent with the recent work by Milani and Rajbhandari (2012). In addition, even when we incorporate a labor adjustment cost into the baseline model to better explain the movement of hours, this augmented model estimated with data on expectations predicts that $25 \%$ of the fluctuations in output can be explained by news shocks. 
Our above insights, which suggest that given the movements of data on expectations, news shocks are not the main source of business cycles, carry over to models with imperfect information. This is important because Coibion and Gorodnichenko (2012a, 2012b) emphasize that rational expectation imperfect information models may be more appropriate than full information models in explaining some features of data on expectations such as persistent forecast errors. However, we argue that regardless of where data on expectations may come from, such as in imperfect information models, news shocks are not a major driver of business cycles. The intuition is as follows. In imperfect information models, agents receive news with a noisy signal. If the signal is accurate, agents recognize that there is a news shock, then the importance of news shocks would be about the same as in the perfect information setting, which is our baseline model. When the signal is noisy, agents do not perceive news shocks accurately, leading to small changes in their expectations. If agents' expectations do not change, agents do not change their behavior until they actually observe the shock. Therefore, news shocks in this case would not be able to generate substantial Pigou cycles. In other words, news shocks are not important in explaining short run fluctuations, and there is no good distinction between news shocks and unanticipated shocks.

Finally, although we only use data on expectations from the Survey of Professional Forecasters (SPF) in our estimation, we argue that our results can be robust to using other data on expectations. First, the SPF forecast data are in line with other forecast surveys such as the Blue Chip, the Consensus Forecast and the Greenbook. Second, the movements of SPF forecast data on output, which we use in the baseline, are also similar to those of Consumer Confidence, which conducts a minimum of 500 interviews each time. In other words, the SPF data can be a proxy for the expectations of agents in the economy. However, since Consumer Confidence survey does not have an explicit relationship with the defined variables in the model, we do not use those data for our estimation.

This paper is directly related to a large literature estimating the roles of news shocks in the business cycles such as Fujiwara et al. (2010), Schmitt-Grohé and Uribe (2012) and Khan and Tsoukalas (2012) which identify the role of news shocks by observing realized macroeconomic variables. Davis (2007) and Gortz and Tsoukalas (2013) address this question using financial variables such as corporate bond spreads. Unlike those papers, we propose a new way to infer news shocks more precisely using data on expectations. Our paper is also connected with the literature which expands the observation set to more precisely estimate the model. In particular, Forni et al. (2012) show that news shocks explain 
less than $25 \%$ of output when including a large number of variables in a FAVAR estimation, which is similar to our results. We are related to the recent literature incorporating data on expectations in a structural model. For example, Barsky and Sims (2012) show that consumer confidence contains news about future fundamentals. Unlike them, we use data on expectations of well-defined macroeconomic variables to directly map model-implied expectations with the data to infer the role of news shocks in the economy. Our estimation finds that over $50 \%$ of data on expectations is explained by news shocks, also suggesting that data on expectations contain news. Other papers such as Del Negro and Schorfheide (2012) and Del Negro and Eusepi (2012) have incorporated data on expectations in their DSGE estimation. However, their models have no news shocks, so they cannot address the question that we are interested in. Finally, we are also related to the work of Hirose and Kurozumi (2012) and Milani and Rajbhandari (2012), which use data on expectations to quantify the role of news shocks. Besides the difference in model specifications, where we use both real DSGE model and model with nominal rigidities and they use model with nominal rigidities only, we provide insights on how and when data on expectations help to distinguish news shocks from unanticipated shocks. Furthermore, we explain how our results can be robust even in an imperfect information setting.

The rest of the paper is organized as followed: Section 2 introduces data on expectations. In section 3, we describe the full model setup, followed by a discussion of the estimation methods including priors and observables in Section 4. Section 5 presents the main estimation results of the model with data on expectations and analyzes how data on expectations help to identify news shocks. We test the robustness of our results with data on expectations of different variables and time period in Section 6. We conclude the paper in Section 7.

\section{Data on Expectations}

This section describes data on expectations that we use to estimate a structural model with news shocks. We make two points about the data. First, these data on expectations are relatively smooth compared to realized data, and do not track the movements of realized data well. Second, they reflect what agents know about the current and future states of the economy.

Our data come from the Survery of Professional Forecaster (SPF) of the Federal Reserve Bank of Philadelphia. In the second month of every quarter, nine to forty professional forecasters are asked to report their forecasts up to four quarters ahead for output and other macroeconomic variables. This dataset contains the longest possible forecast in quarterly frequency starting as early as 1968Q4 
for output. Other surveys such as the Blue Chip, Consensus or Livingston forecast surveys are either in monthly frequency starting late 1980s or in semiannual frequency. We use the mean of forecasts across individual forecasters as our data on expectations.

First, we find that data on expectations are smooth relatively to realized data, and do not resemble realized data in most of the sample period. We plot in Figure 2 the four-quarter output growth rate together with the corresponding two- and four-quarter ahead data on expectations, denoted by $F_{t-2} \Delta \ln y_{t-4, t}$ and $F_{t-4} \Delta \ln y_{t-4, t}$, respectively. We observe that the movements of data on expectations do not exhibit large variations over time, especially the four-quarter ahead data on expectations. Even though the two-quarter ahead data on expectations are slightly more volatile and track realized data better than the four-quarter ahead data on expectations, both are smoother than realized output. This pattern is clearer when we calculate the standard deviation of quarterly forecast relative to realized data, displayed in Table 1 . On average, only $5 \%$ of the output growth rate fluctuations are anticipated one year in advance. Furthermore, the correlation of the data on expectations of output and realized output growth rates are small.

Second, these data on expectations can represent actual expectations of agents in the economy. We find that the SPF data are similar to other forecast survey data, as plotted in Figure 3 the four-quarter ahead forecast of the four-quarter growth rate of output from different surveys such as the Blue Chip, the Consensus Forecast and the Greenbook. The SPF forecast data of output growth rate move in a similar direction and magnitude as other surveys. This pattern is also true for other macroeconomic variables such as consumption and investment. There is a potential concern that these forecasters are reserved when writing down their forecasts. However, Coibon and Gordonichenko (2012) present evidence against the hypothesis that these agents smooth their forecast. Other papers in the literature such as Zarnowitz and Braun (1993) and Ang et. al. (2007) also find that survey forecast is more accurate for most variables and spans than forecasts obtained from VAR and other forecasting models. Besides, data on expectation suggests that agents incorporate their information into their forecast. For example, forecast data move significantly in the 1970s period. Also, in the second oil price shock in the 1980 recession, agents were able to predict a year in advance that output would decline. The predicted decline in output is close to the realized decline in output, especially when the forecast was made two quarter before the recession. The reason is that forecasters knew that the war in the Middle East would disrupt the supply of oil. Also, OPEC countries announced that they would increase the price of oil for the next year. Therefore, forecasters incorporated these information to 
their forecast and could predict a recession in the US one year in advance. Another episode is during the boom in early 1990s. This is the period where agents were optimistic with the New Economy. Therefore, they could forecast well the boom after the recession in 1991. These instances suggest that forecasters actually incorporate available information into their forecast. Finally, we plot in the Appendix the SPF four-quarter output growth rate forecast against a measure of expected changes in business conditions in the next 12 months taken from the Michigan Survey of Consumer Confidence. We find that the movements of these two series are similar over time, suggesting that the SPF forecast data represent what agents expect in the economy.

Finally, consistent with previous literature, data on expectations exhibit persistent forecast errors. The last section of Table 1 displays the persistence of forecast errors within our sample. There are some persistence in the forecast errors but they are only significant in horizons three and four of the output forecast. Although persistence forecast errors are not consistent with rational perfect information model, we argue later that this feature of data on expectations does not affect our results. A recent growing literature such as Coibion and Gorodnichenko (2012a and 2012b) suggests that rational expectation imperfect information models can explain the persistent forecast errors. Therefore, we explore later in the paper that adding imperfect information may not change our results.

\section{The Model}

To investigate the role of news shocks in business cycles, we estimate a standard real DSGE model as in Schmitt-Grohé and Uribe (2012) using Bayesian methods. We adopt this model as our baseline model as it is the first and influential paper in structural estimation using realized data to identify news shocks. Nevertheless, we show later that the results from our baseline model are robust in other models also.

The model is a medium-scaled real business cycle model buffeted by seven types of shocks: preference shocks, neutral stationary and permanent technology shocks, stationary and permanent investment-specific shocks, wage markup shocks and government spending shocks. Each shock has an unanticipated component as well as four- and eight-quarter ahead news components. A $k$-quarter ahead news shock means that the agents know at time $t-k$ that the shock will materialize at time $t$. We describe briefly the model below.

The model consists of a continuum of agents who maximize the expected lifetime utility defined 
over the sequences of consumption $C_{t}$ and hours worked $h_{t}$ :

$$
\max E_{0} \sum_{t=0}^{\infty} \beta^{t} b_{t} \frac{\left[C_{t}-\kappa C_{t-1}-\psi h_{t}^{v} N_{t}\right]^{1-\sigma}-1}{1-\sigma}
$$

where $b_{t}$ is an exogenous preference shifter, $\kappa$ is the habit in consumption, $\psi>0, v>0$ is related to Frisch elasticity, and $N_{t}$ is a geometric average of current and past habit-adjusted consumption levels. The law of motion of $N_{t}$ is given by:

$$
N_{t}=\left(C_{t}-\kappa C_{t-1}\right)^{\gamma} N_{t-1}^{1-\gamma}
$$

This preference is introduced by Jaimovich and Rebelo (2009). It nests as special cases the two classes of preferences used in the literature while preserving long run balanced growth path. The parameter $\gamma$ governs the wealth elasticity of labor supply. When $\gamma=1$, we obtain the preference of the King, Rebelo and Plosser (1988). When $\gamma \rightarrow 0$, there is no wealth effect on labor supply in the absence of habit, the utility function is of the same form as Greenwood, Hercowitz and Huffman (1988). Jaimovich and Rebelo (2009) shows that $\gamma$ has to be small in order to generate comovement among output, hours, consumption and investment in response to news shocks. We estimate this parameter.

Households are assumed to hold capital. The capital stock $K_{t}$ evolves over time according to the following law of motion:

$$
K_{t+1}=\left(1-\delta\left(u_{t}\right)\right) K_{t}+a_{t}^{i}\left[z_{t}^{i} I_{t}\right]\left[1-S\left(\frac{z_{t}^{i} I_{t}}{z_{t-1}^{i} I_{t-1}}\right)\right]
$$

where $I_{t}$ is gross investment in consumption unit, $a_{t}^{i}$ is the exogenous stationary shock to the technology transforming investment goods to capital goods (stationary IST) and $z_{t}^{i}$ is the exogenous stochastic IST shock. Therefore, $z_{t}^{i} I_{t}$ is in investment good unit. The growth rate of $z_{t}^{i}$ is denoted by $\ln \mu_{z i, t}=\ln \left(\frac{z_{t}^{i}}{z_{t-1}^{i}}\right)$. Given this formulation, the price of investment is related to $z_{t}^{i}$ by $z_{t}^{i}=\frac{P_{t}}{P_{t}^{i}}$.

Households can choose the utilization of capital, denoted by $u_{t}$, which means that the effective capital used every period is $u_{t} K_{t}$. However, higher utilization of capital comes with the cost of faster depreciation $\delta\left(u_{t}\right)$. The functional form of depreciation rate is:

$$
\delta\left(u_{t}\right)=\delta_{0}+\delta_{1}\left(u_{t}-1\right)+\frac{\delta_{2}}{2}\left(u_{t}-1\right)^{2},
$$


where $\delta_{0}>0$ is the depreciation rate at steady state, $\delta_{1}$ is set to be consistent with $u=1$ at steady state, and $\delta_{2}>0$ is the sensitivity of capital utilization variation to the rental rate of capital.

There is a cost of adjusting investment in the quadratic form as in Christiano, Eichenbaum and Evans (2005):

$$
S\left(\frac{z_{t}^{i} I_{t}}{z_{t-1}^{i} I_{t-1}}\right)=\frac{s}{2}\left(\frac{z_{t}^{i} I_{t}}{z_{t-1}^{i} I_{t-1}}-\mu_{I}\right)^{2},
$$

where $s>0$ is a parameter and $\mu_{I}$ is the investment growth rate at the steady state.

The households maximize their expected utility subject to the following budget constraint:

$$
C_{t}+I_{t}=D_{t}-E_{t} r_{t, t+1} D_{t+1}+w_{t}^{h} h_{t}+R_{t}^{k}\left(u_{t} K_{t}\right)-T_{t}+\Pi_{t}
$$

where $w_{t}^{h}$ is the wage received by the households, $R_{t}^{k}$ is the rental rate of effective capital, $D_{t}$ is the bond holdings and $r_{t, t+1}$ is the stochastic discount factor such that $E_{t} r_{t, t+1} D_{t+1}$ is the period- $t$ price of a random payment $D_{t+1}$ in period $t+1, T_{t}$ is the lump sum tax levied by the government to finance government expenditure, and $\Pi_{t}$ is the profit accruing to households from the labor union.

Final good $Y_{t}$ is produced by a monopolist using the following homogeneous degree 1 production function:

$$
Y_{t}=a_{t}^{n}\left(u_{t} K_{t}\right)^{\alpha_{k}}\left(z_{t}^{n} h_{t}\right)^{\alpha_{h}}\left(z_{t}^{n} L\right)^{1-\alpha_{k}-\alpha_{h}}
$$

where $K_{t}$ and $h_{t}$ denotes the amount of capital and labor employed, $L$ is a fixed factor that can be interpreted as land, $a_{t}^{n}$ is the neutral stationary technology shock and $z_{t}^{n}$ is the neutral laboraugmenting technological progress. The fixed factor of production allows for decreasing returns to scale in the variable factors of production. The growth rate of $z_{t}^{n}$ is denoted by $\ln \mu_{z n, t}=\ln \left(\frac{z_{t}^{n}}{z_{t-1}^{n}}\right)$.

In the labor market, each household is a monopolistic supplier of differentiate labor $h_{t}(j)$. A large number of employment agencies combine the differentiated labor $h_{t}(j)$ into a homogeneous labor input sold to intermediate firms according to:

$$
h_{t}=\left[\int_{0}^{1} h_{t}(j)^{\frac{1}{\eta_{w, t}}} d j\right]^{\eta_{w, t}}
$$

where $\eta_{w}$ is wage markup. The desired markup of the wage over the household's marginal rate of substitution follows an exogenous stochastic process. Profit maximization by the perfectly competitive 
employment agencies implies that the labor demand function is

$$
h_{t}(j)=\left(\frac{W_{t}(j)}{W_{t}}\right)^{-\frac{\eta_{w}}{\eta_{w}-1}} h_{t},
$$

and the wage paid by firms for their labor input is:

$$
W_{t}=\left[\int_{0}^{1} W_{t}(j)^{-\frac{1}{\eta_{w}-1}} d j\right]^{-\left(\eta_{w}-1\right)}
$$

From the labor supply side, the problem of labor supply of type $j$ is to maximize $\left(W_{t}-w_{t}^{h}\right) h_{t}(j)$ subject to the labor demand function above. Then, the optimal condition requires

$$
w_{t}^{h}=\frac{W_{t}}{\eta_{w, t}}
$$

which means that the wage rate that households receive is smaller than the wage paid by firm. The profit of employment agencies are rebated in lump-sum to households.

We assume government spending is determined exogenously and finances these spendings by a lump-sum tax. Government spending $G_{t}$ has a trend $X_{t}^{G}$ so $g_{t}=\frac{G_{t}}{X_{t}^{G}}$ is the detrended government spending. The trend of government spending is assumed to be smoother than the trend of output $X_{t}^{Y}$ and is given by:

$$
X_{t}^{G}=\left(X_{t-1}^{G}\right)^{\rho x g}\left(X_{t-1}^{Y}\right)^{1-\rho x g},
$$

where $\rho x g$ is the parameter determining the smoothness of $X_{t}^{G}$.

All seven shocks, namely stationary and permanent neutral technology shocks, stationary and permanent investment-specific technology (IST) shocks, preference shocks, wage markup shocks and government spending shocks, include an unanticipated and news component. The news component consists of four- and eight-quarter ahead news shocks, meaning that the agents receive information at time $t$ that the shock will happen at time $t+4$ for four-quarter ahead news shocks and $t+8$ for eight-quarter ahead news shocks. Therefore, all exogenous shocks $x_{t}$ evolve over time using the following law of motion:

$$
\ln \left(\frac{x_{t}}{x}\right)=\rho_{x} \ln \left(\frac{x_{t-1}}{x}\right)+\varepsilon_{x, t}^{0}+\varepsilon_{x, t}^{t-4}+\varepsilon_{x, t}^{t-8}
$$

where $x=\left\{a_{n}, \mu_{z n}, a_{i}, \mu_{z i}, \eta_{w}, b, g\right\}, \varepsilon_{x, t}^{0} \sim N\left(0,\left(\sigma_{x}^{0}\right)^{2}\right)$ denotes unanticipated shocks known at time 
$t, \varepsilon_{x, t}^{t-4} \sim N\left(0,\left(\sigma_{x}^{4}\right)^{2}\right)$ and $\varepsilon_{x, t}^{t-8} \sim N\left(0,\left(\sigma_{x}^{8}\right)^{2}\right)$ are the four- and eight-quarter ahead news shocks, respectively.

\section{Estimation Method}

We estimate the model using Bayesian methods with U.S. data between 1955Q1 and 2006Q4. The length of data is dictated by the available observables. We later show that our results are robust to different data period. As common in the literature, we calibrate parameters that are related to the steady state and often calibrated in the literature, as shown in Table 2. The discount factor is set to be 0.99 . The capital elasticity of the production, $\alpha$, is set to be 0.225 , implying that the labor share is 0.67 given the degree of decreasing to scale. This setting does not matter for our results as our robustness check shows that a constant returns to scale production without fixed capital $L$ would yield similar results. Following previous literature, we adopt log utility function, i.e. the risk aversion parameter, $\sigma$, is 1 . The depreciation rate at the steady state, $\delta_{0}$, is 0.025 . We calibrate $\delta_{1}$ such that in the steady state, utilization is 1 . The parameter $\psi$ is then set such that hours worked at the steady state is 0.2 . The steady state growth rates of output and investment, and the steady state share of government spending in total output are set to be equal to the corresponding U.S. data average between 1955Q1 and 2006Q4.

The rest of the parameters are estimated using Adaptive Random Walk Metropolis Hasting as discussed in Haario et. al. (2001) to obtain a more efficient estimation. Following Schmitt-Grohé and Uribe (2012), we set our priors to be the same as theirs as reported in Table 2. Given the priors for the parameters and the sample data $Y$, we can draw from the posterior distribution of estimated parameters, denoted as $\Theta$. This requires the evaluation of the product of the likelihood function and prior distributions, which is denoted by $L(Y \mid \Theta) P(\Theta)$. The likelihood function $L(Y \mid \Theta)$ is found numerically after solving the model using first order approximation method in Schmitt-Grohé and Uribe (2004). We obtain the following state space form:

$$
\begin{aligned}
X_{t+1} & =h_{x}(\Theta) X_{t}+\eta(\Theta) \varepsilon_{t} \\
o b s_{t} & =g_{x}(\Theta) X_{t}+m e_{t}^{o b s}
\end{aligned}
$$

where $X_{t}$ is a vector of state variables and $\varepsilon_{t}$ is a vector of structural shocks with $N(0, I)$ and obst are the observables discussed below, and $m e_{t}^{o b s}$ are the corresponding measurement errors. 
To understand how data on expectations change the inferences about the news shocks, we estimate the model with two observable sets. The first set includes seven observables:

$$
\left[\Delta \ln y_{t-1, t}, \Delta \ln c_{t-1, t}, \Delta \ln I_{t-1, t}, \Delta \ln h_{t-1, t}, \Delta \ln T F P_{t-1, t}, \Delta \ln p_{i n v, t-1, t}, \Delta \ln G_{t-1, t}\right],
$$

which is the quarterly growth rates of output, consumption, investment, hours, TFP, price of investment and government spending, respectively. These observables are matched with the corresponding model concepts. We allow measurement errors, $m e_{t}^{y}$, for output growth rate only to take into account the fact that we ignore the net exports component of output. The measurement error for output growth is assumed to be an i.i.d. innovation with mean zero and standard deviation $m e^{y}$, which is also estimated. We restrict $m e^{y}$ to be at most $10 \%$ of the standard deviation of output growth rate.

The second set of observables consists of nine observables: the seven observables above and the two- and four-quarter ahead cumulative data on expectation for output growth rate. The cumulative data on expectation is defined as follows: let $\Delta \ln y_{t, t+k}$ denote the average growth rate of output between $t$ and $t+k$, i.e. $\Delta \ln y_{t, t+k}=\frac{\ln \left(\frac{y_{t+k}}{y_{t}}\right)}{k}$ for $k=1,2,3,4$. Then, $E_{t} \Delta \ln y_{t, t+k}$ is the model expectation at horizon $k$ of the cumulative growth rate made at time $t$, and $F_{t} \Delta \ln y_{t, t+k}$ is the forecast of $\Delta \ln y_{t, t+k}$ at horizon $k$ made at time $t$. The data and the model concept of expectations are linked by the following equations:

$$
\begin{aligned}
& F_{t} \Delta \ln y_{t, t+2}=E_{t} \Delta \ln y_{t, t+2}+m e_{t}^{y 2}, \\
& F_{t} \Delta \ln y_{t, t+4}=E_{t} \Delta \ln y_{t, t+4}+m e_{t}^{y 4},
\end{aligned}
$$

where $m e_{t}^{y 2}$ and $m e_{t}^{y 4}$ are the measurement errors for two- and four-quarter ahead data on expectations, respectively. The measurement errors for data on expectations are assumed to be i.i.d. innovation with mean zero and standard deviations $m e^{y 2}$ and $m e^{y 4}$, respectively. We allow $m e^{y 2}$ and $m e^{y 4}$ to be no more than $10 \%$ of the standard deviation of the corresponding data on expectations. Since we do not have data on expectations dating back to 1955Q1, we treat data on expectations as missing data points between 1955Q1 and 1970Q1. We also show in our robustness check that these missing data points do not affect our results.

We numerically evaluate the likelihood function $L(Y \mid \Theta)$ by applying the Kalman filter to this state space form. Evaluating prior distribution $P(\Theta)$ is straightforward using the known distributions discussed above. In Adaptive Random Walk Metropolis Hasting method, we update the chains 
multiple times to increase efficiency of the estimation. We perform several checks to make sure the estimation has converged. All of our results below are computed from four chains of 50,000 draws each. The results do not change if we use longer chains.

\section{Estimation Results}

This section presents the main estimation results of the model. We show that the model estimated with data on expectations can fit the data as well as the model estimated without data on expectations. However, news shocks play a much less important role in explaining the fluctuations of macroeconomic variables in the model estimated with data on expectations than in without data on expectations. We then interpret the results and discuss how data on expectations help to identify news shocks in the model.

\subsection{Estimated Parameters and Model Fit}

First, the parameters governing the investment adjustment cost, habit, wealth elasticity of labor supply and utilization cost do not change when estimated with data on expectations. As display in Table 3, the posterior median of the parameters estimated with and without forecast for $s, \kappa, \gamma$, and

$\frac{\delta_{2}}{\delta_{1}}$ are similar between two cases. This suggests that data on expectations do not change inferences about the model parameters.

Second, the main differences between the two cases are the shock parameters, suggesting that adding data on expectations mostly changes the inferences about the shocks driving the economy. The standard deviations of news for both government spending and preference shocks at four- and eight-quarter ahead are much smaller estimated with data on expectations than without data on expectations while the standard deviations of the unanticipated shocks become larger. This result indicates that the role of news about preference and government spending shocks is smaller than before. However, the standard deviations of some news shocks become larger, which means that data on expectations change the timing of shocks. For example, the standard deviation of the eight-period ahead wage markup news shocks is larger in the case estimated with data on expectations than in the case without data on expectations. Importantly, the estimated parameters with data on expectations are more precisely estimated than without data on expectations: the 5-95\% credible sets are smaller. This result suggests that data on expectations add strong restriction to the estimation to recover the 
states of the economy including news shocks.

In terms of model fit, we find that the model estimated with data on expectations fit the data reasonably well, similar to the model estimated without data on expectations. In Table 4, we report the median of the posterior distribution of the population second moments computed from the last 200,000 draws of the posterior distribution in both cases together with the corresponding empirical second moments. In both cases, the model is able to replicate most of the second moments of the data except for the persistence of hours and the correlation of hours with output. We conclude that adding data on expectations increases the precision of the estimated parameters and does not worsen the model fit.

\subsection{The Role of News Shocks in Business Cycles}

The first main result of the paper is that the model estimated with data on expectations predicts a smaller contribution of news shocks than the model estimated without data on expectations. To make the comparison clear, we report in the first and second columns of Table 5 the shares of the unconditional variances of output, consumption, investment and hours growth rates explained by all types of news shocks in the model estimated without and with data on expectations between 1955Q1 and 2006Q4. All of these results are computed at the mean of the posterior distribution of the variance decomposition, together with the $5-95 \%$ confidence interval.

The overall contribution of news shock is about half of the estimated contribution without data on expectations. News shocks account for about $24 \%$ of output growth rate. When decomposing the contribution of each type of news shocks, we find that news about preference, government spending shocks, and wage markup shocks to some extent become much less important than in the model estimated without data on expectations. For example, news about preference shocks explain about $1 \%$ of output variation compared to $9 \%$ without data on expectations, and news about wage markup shocks explain only $7.5 \%$ of output variation, which is half of the contribution estimated without data on expectations.

To gauge how much news shocks explain past business cycles, we compute the historical decomposition of the U.S. output between 1955 and 2006 and find that most of the business cycles in our sample are not driven by news shocks. Figure 5 plots the historical decomposition for news shocks along with the time series of the four-quarter U.S. output and the corresponding four-quarter ahead forecast. In our sample, news shocks do not explain much of past business cycles. Two exceptions 
are the 1980-81 recession and 1992-93 expansion. This result is consistent with the timing of data on expectations which show that agents could predict a year in advance correctly the movements of output. For example, in the second oil price shock, agents read news about the Iranian war in 1979 and announcement about oil prices, so they could anticipate a year in advance that output would decline, which was true in 1980. Therefore, news shocks are estimated to be important in that recession. However, the fact that news shocks do not account for most of the output fluctuations during this sample period suggests that news shocks are not the main source of business cycles.

Data on expectations have a large impact on the contributions of news shock to both consumption and government spending: news shocks are negligible in the model estimated with data on expectations. Only $11 \%$ of the consumption volatility is explained by news shocks compared to $53 \%$ estimated without data on expectations. Similarly, news shocks account for less than $8 \%$ of the variations in government spending, in contrast with $58 \%$ estimated without data on expectations. These substantial declines in the contribution of news shocks to consumption and investment are because the role of news for preference and government spending shocks is much smaller, $4 \%$ and $5 \%$ respectively, while unanticipated shocks of the same kind become more important.

However, even when estimated with data on expectations, news shocks remain relatively important in explaining the movements of hours and investment, contributing $46 \%$ and $28 \%$ to the variations of hours and investment growth rates, respectively. Without data on expectations, news shocks explain $76 \%$ and $35 \%$ of hours and investment, meaning data on expectations also reduce the importance of news shocks to aggregate fluctuations but to a lesser extent compared to consumption and government spending. The reason for why news shocks are still important for these variables is that the important news shocks, stationary investment specific technology shocks and wage markup shocks, are able to generate the delayed responses of hours to output as documented in Schmitt-Grohé and Uribe (2012). These news shocks cause firms and household to adjust immediately while labor supply does not adjust much on impact. Instead, the response of hours is negligible and takes place mostly when the shock is realized. Therefore, the model assigns a non-negligible role to these news shocks.

Besides changing the total contribution of news shocks to aggregate fluctuations, data on expectations also lead to a different inference about the timing of news shocks. For example, with data on expectations, the eight-quarter ahead wage markup news shocks and unanticipated wage markup shocks are estimated to play the most important role while without data on expectations, four-quarter ahead wage markup news shocks are the most important. Similarly, the four- and eight-quarter ahead 
news shocks explain equal fractions of the aggregate fluctuations while the model estimated data on expectations assigns a larger role to the eight-quarter ahead news shocks. Taken together, these results suggest that model estimated with data on expectations change inferences about news shocks significantly.

Lastly, we find that news shocks explain a large share of the volatilities of data on expectations. More specifically, $53 \%$ and $57 \%$ of the fluctuations in the two-quarter and four-quarter ahead forecast of output growth rate are explained by news shocks. This result is consistent with our intuition that forecast contains information about news shocks. It is also similar in spirit to Barsky and Sims (2010), who show that consumer confidence contains news about the future productivity. In our case, the important news shocks for the fluctuations of data on expectations are news about wage markup and stationary investment-specific technology shocks.

\subsection{The precision of the estimates}

The second main finding of our paper is that the contribution of news shocks for all variables are much more precise when estimated with data on expectations than without data on expectations. We plot in Figure 4 the posterior distributions of the shares of output, consumption, investment, hours and government spending explained by news shocks with and without data on expectations as well as the prior distribution. The posterior distributions of the shares of the unconditional variance of the growth rates of all the variables are tighter with data on expectations. The difference is especially clear for consumption and government spending where the posterior distributions without data on expectations are flat between 0 and $100 \%$ while those with data on expectations are tightly estimated to be under $20 \%$. The distributions of the share of news shocks to output and investment are also tighter, further suggesting that data on expectations add strong restrictions to the estimation of the role of news shocks in the economy.

\subsection{The Importance of News Shocks in the Short Run}

A third important finding of our paper is that news shocks play a negligible role in explaining short run fluctuations. We focus on horizons up to two years because this is when agents know that the shock will happen but the shock has not materialized. As shown in Figure 6 which plots the forecast error variance decomposition of news and unanticipated shocks for output, consumption, investment and hours, news shocks explains less than $10 \%$ of all the macroeconomic variables for up to two 
year horizons. The intuition behind this result is that although some of the news shocks such as news about future productivity shocks can cause changes in output today, these news shocks play a negligible role in business cycles as discussed above. Additionally, we show later that many of the news shocks such as government spending news shocks do not cause agents to adjust their current behavior significantly, resulting in a small fraction of output being explained by news shocks in the short run. The forecast error variance decomposition for hours illuminates our intuition clearly. As explained above, the volatilities of hours are mostly explained by news about wage markup shocks, which do not affect hours much until wage markup shock materializes. Therefore, even though news shocks explain nearly half of the movements in hours in the long run, it explains almost nothing of hours in the short run.

We obtain the finding about the negligible role of news shocks in the short run only with data on expectations. Without data on expectations, news shocks in the short run explain up to $25 \%$ of output fluctuations. However, as adding data on expectations reduces the importance of news shocks overall, the role of news shocks in the short run becomes much smaller than estimated without data on expectations.

\subsection{The Role of Data on Expectations in Inferring News shocks}

We now explain how data on expectations change the inference about news shocks and causes our estimates to be much more precise. The simple intuition behind our results is as follows. If news shocks were a major driver of business cycles, expectations would exhibit movements that resemble realized output. Since data on expectations do not have large movements over time and do not resemble realized output, news shocks cannot be the main source of fluctuations. Additionally, there are types of news shocks in the model that we would not be able to distinguish from without data on expectations.

To illustrate our intuition above, we compare how expectations respond to an unanticipated shock versus a news shock. We plot in Figure 7 the impulse responses of output growth rate to both an unanticipated and a four-quarter ahead news innovation at time one in each of the seven shocks in the mode 1 . The impulse response functions are calculated at the mean of the posterior estimates without data on expectations.

Expectations do not respond much to unanticipated shocks happening in period one relative to

\footnotetext{
${ }^{1}$ Given the responses of output growth rate, the responses of the four-quarter ahead expectations at time $t$ are the same as the responses of output growth rate at time $t+4$ in our perfect information setting.
} 
realized output, suggesting that unanticipated shocks are consistent with the movements of data on expectations. The largest response of output growth rate is at period one and two after an unanticipated shock, then output growth rate goes back to the steady state. In other words, when agents form their expectations in period 1 about output growth rate in period five, their expectations do not change as much as realized output. This type of responses can generate the pattern of expectations found in the data: data on expectations do not move much relative to realized output, and do not track actual movements of realized output so well.

In contrast, expectations respond strongly to news shocks, implying that observing data on expectations puts a strong restriction on the size of news shocks. In response to the four-quarter ahead news about future fundamentals, output growth rate responds the largest in period five when the shock materializes, meaning expectations would react the strongest in period 1. Especially for news about demand shocks such as news about government spending and preference shocks, there is almost no response of output in periods one to four when agents receive news in period one that the shock will happen in period five. Not until the shock materializes in period five does output growth rate increase significantly. In other words, the size of news shocks has a strong implication about the movements of expectations. If news shocks are large, expectations would move strongly. Therefore, as data on expectations are relatively smooth, any news shocks that cause substantial change in expectations would not be important.

Besides imposing the restriction on the size of news shocks, data on expectations also help to distinguish many news shocks from the unanticipated shocks of the same kind, making the estimation much more precise. In particular, without data on expectations, it is hard to separate news about demand shocks from unanticipated demand shocks of the same kind. The reason is as follows. We focus on the impulse responses of output growth rate to preference shocks. As shown in Figure 7, output growth rate increases right in period one when preference shock happens and expectations for output growth rate in period five do not change much as the effect of preference shocks dies down. In contrast, when agents receive news in period one that there will be a positive preference shock in period five, output growth rate responds little and only increases when preference shock actually happens in period five. In other words, whether or not agents receive any news about preference shocks does not change their behavior significantly until the shock happens. We call this type of news shocks news shocks that do not generate substantial "Pigou cycles", which are aggregate fluctuations before the shock materializes. The responses of output growth rate to news about preference shocks 
look like those to an unanticipated preference shock shifting by four periods. Therefore, without data on expectations, it is hard to distinguish news from unanticipated shocks. As we see in Figure 4, without data on expectations, the posterior distributions of the shares of consumption and government spending attributed to news shocks are almost the same as the prior distributions, implying that the estimation without data on expectations is not able to identify news shocks well. Once we add data on expectations into the observable set, the posterior distributions are much more precise because we are now able to separate news shocks, which change expectations without changing output significantly, from unanticipated shocks, which change output significantly. As news about demand shocks cause substantial changes in expectations, these news shocks are clearly identified as not important. This explains why in Figure 4, the posterior distributions of the share of aggregate variables are much more tightly estimated and lower than when estimated without data one expectations.

\subsection{The Role of Data on Expectations in Inferring News Shocks: Robustness}

A natural question arises from our analysis is when data on expectations do not lead to a decline in the role of news shocks in business cycles. In other words, is there any situation in which expectations do not move much and do not track movements of realized output as in the data while news shocks are still important. We argue that for news shocks that generate strong responses of output before the shock materializes, i.e. shocks that can generate substantial "Pigou cycles", including data on expectations as observables in the estimation may not change the contribution of news shocks compared to the results obtained in the model estimated without data on expectations. The reason is that when there is a strong immediate response of endogenous variables to news shocks before shocks actually materialize, news shocks work like unanticipated shocks. Then, expectations at horizon four for output growth rate may not have large movements, which is consistent with data on expectations. As news shocks account for the movements of data on expectations, the contribution of those news shocks cannot be nil.

Combining with our analysis above, it is clear that data on expectations would restrict the importance of the types of news shocks that do not generate Pigou cycles, which are news about demand shocks in our case. On the other hand, news shocks that can generate significant Pigou cycles, such as news about future productivity shocks can still be an important source of fluctuations. However, in general, only under extreme parameterization can we obtain news shocks that generate such strong Pigou cycles that data on expectation cannot help to better identify. As shown in Figure 7, for 
all types of news shocks including news about productivity shocks, expectations of output growth rate fluctuate significantly as the largest impact happens at the time that the shock materializes. Therefore, in general, data on expectations are helpful in inferring news shocks.

We make a final note that one example of the type of models that generates strong immediate response of output is model with strong sticky price. The intuition is that in an extreme case when prices do not change at all, output will increase immediately after a technology news shock. Since agents know that technology will increase in the future, they demand more goods from today. The demand is higher when price is fixed, causing output to increase strongly from today. In this case, four-quarter ahead expectations of output growth rate will not change. Adding data on expectations may not decrease the importance of news shocks. However, as we show in our Robustness section, data on expectations are still helpful in our estimation of the the baseline model augmented with nominal rigidities.

\section{Robustness}

This section provides the robustness of our results with respect to different data period, the horizon of data on expectations, types of data on expectations, types of realized data, i.e. real-time firstobserved data instead of the revised data 2 . We also show that our result is robust with a wider range of models when we include nominal rigidities or labor adjustment cost in the model. Finally, we offer intuition why our results do not change under imperfect information assumption.

\subsection{Data Period}

We first re-estimate the baseline model with data from 1970Q1 to 2006Q4 to avoid missing data on expectations. We report the result for this case in Column 1 of Table 7. Similar to the baseline model, our estimation of the model with data on expectations predict that news shocks account for nearly $27 \%$ of output fluctuations, $15 \%$ of consumption, $30 \%$ of investment and $40 \%$ of hours. The posterior distributions of the shares of the variances of these variables are also tightly estimated. Consistent with our explanation above, news about demand shocks are negligible. Additionally, news shocks explain little in short run fluctuations, similar to our baseline estimation. This result suggests that data on expectations are informative enough that whether to include the 1955Q1 to 1969Q4 or not

\footnotetext{
${ }^{2}$ We have also checked that our results are robust with constant returns to scale production function, as well as 1984Q1-2006Q4 period.
} 
does not alter the conclusion about the role of news shocks in business cycles.

\subsection{First released realized data instead of revised data}

Since agents form expectations when they only know the first release of the current quarter realized data, a sensible exercise is to use first release realized data instead of the revised data as in our baseline model. Column 2 of Table 7 presents the result of the baseline model estimated with output, consumption, investment and government spending data between 1955Q1 and 2006Q4 using its first vintage from the Federal Reserve Bank of Philadelphia. Again, consistent with our baseline model, news shocks explain about $18 \%$ of output growth rate, $5 \%$ of consumption, $28 \%$ of investment, and $45 \%$ of hours. All of our results reported in the baseline model carry through in this case also. The fact that our results are robust with respect to the data vintage suggests the robustness of our insights, that data on expectations are informative about the role of news shocks in business cycles.

\subsection{Using Data on Expectations of Different Horizons}

We next show that our results are robust when using only four-quarter ahead data on expectations only or all of the one-, two-, three- and four-quarter data on expectations, suggesting that fourquarter ahead data on expectations alone are informative about the role of news shocks. We report in Columns 3 and 4 of Table 7 the estimated contribution of news shocks to output, consumption, investment, hours and government spending. We find that compared to the baseline model, both cases predict similar importance of news shocks with a similar precision. Although using all horizons of data on expectations lead to tighter estimated contribution of news shocks to consumption and government spending, the rest of the results remains the same as our baseline model. What this result tells us is that four-quarter ahead data on expectations alone are helpful in inferring news shocks. The intuition for this result is that we include four- and eight-quarter ahead news shocks in the model. Therefore, four-quarter ahead data on expectations summarizes the information agents have about the economy a year ahead. Having eight-quarter ahead data on expectations can be more informative about the timing of eight-quarter ahead news shocks. However, four-quarter ahead expectations also contain the information about eight-quarter ahead news that agents have received four quarters ago, so four-quarter expectations can still be informative about news shocks with horizons longer than four quarters. If, on the other hand, the model includes two-quarter ahead news shocks, data on expectations with shorter horizons are necessary to identify these news shocks. 


\subsection{Additional Data on Expectations as Observables}

To examine if using additional data on expectations changes our results, we re-estimate the baseline model using two- and four-quarter ahead data on expectations of not only output but also consumption, investment and government spending. We report in Column 5 of Table 7 the estimation results. In this case, news shocks contribute to about $20 \%$ of output fluctuations, less than $10 \%$ of consumption and government spending. Consistent with our baseline results, news remains an important source of uncertainty for investment and hours. Other results that we report above in our baseline estimations also hold in this case. We note that the additional data on expectations of government spending makes the contribution of news shocks to government spending even smaller than the baseline estimation, i.e. the role of news shocks is close to zero. The fact that our results do not change when adding more data on expectations as observables suggest that data on expectation for output are already informative about the role of news shocks. Together with the robustness check of different horizons of data on expectations for output, we conclude that four-quarter ahead data on expectations for output alone are useful in our estimation.

\subsection{Labor Market and News shocks}

Our next two robustness check exercise deals with the extension of the baseline model to further show the usefulness of data on expectations. In the first exercise, to explain the persistence of hours which the baseline model misses, we augment the model with a labor adjustment cost and estimate the model with data on expectations. We find that our results presented above are robust but news shocks play a less significant role in explaining the movement of hours.

To motivate the extension of the model, we show that (1) the large contribution of news shocks to hours fluctuations may not be consistent with data on expectations of the labor market, (2) the estimated baseline model is not able to replicate the persistence of hours in the data. First, in our baseline estimation, since news shocks are important for hours, the model-implied expectations of hours would have large movements that resemble realized hours movements, which can be compared with data on expectations of hours. However, since we do not observe long enough data on expectations for employment, we resort to the change in unemployment rate and its expectations in the SPF survey plotted in Figure 8. Similarly to output, data on expectations of the change in unemployment rate are smooth and do not track the movements of realized unemployment rate change. We interpret this graph as some evidence that agents in the economy do not have much information about 
future fundamentals. In contrast, when the model is estimated with data on expectations of output, the four-quarter ahead model-implied expectations of hours growth rate, plotted in Figure 9, have significant movements over time that track the movements of realized hours growth rate well. The reason is that news shocks explain $46 \%$ of hours fluctuations. This evidence, together with the fact that the model wants news about markup shocks to explain the delayed responses of hours relative to other macroeconomic variables, suggests that news shocks being important for hours may be a result of the model's nature that it tries to explain hours movements.

Second, news shocks are important for hours to explain the persistence and delayed responses of hours relative to output. As we look at how the second moments implied by the model in Table 4, we find that the persistence of hours is much lower than in the data. However, conditional on wage markup news shocks, we find that this type of news shocks help to explain the persistence of hours and the delayed response of hours compared to output. This further suggests that there is a tension between fitting the movement of hours worked and the movement of expectations. Therefore, the estimation assigns a non-negligible role of news shocks to hours. Without any change in the model in the labor market to explain hours worked, the model needs these types of news shock to explain the data even when we observe data on expectations? However, since the model still falls short in explaining persistence of hours, a small change in the model to explain the persistence of hours may change our results.

Motivated by the two observations above, we augment the baseline model to include a labor adjustment cost and re-estimate this augmented model, "model with LAC". For simplicity, the labor adjustment cost is of the form as follows:

$$
\phi\left(h_{t}, h_{t-1}\right)=\phi_{H}\left(h_{t}-h_{t-1}\right)^{2}
$$

where $\phi_{H}>0$ is a parameter governing the adjustment cost. Labor adjustment cost can change the model's behavior in two ways. The first is that the responses of hours can be more persistent and delayed in response to unanticipated shocks depending on how large the labor adjustment cost is. This implies that news shocks may not be necessary to explain hours. However, labor adjustment cost can also make news shocks more important. The reason is that upon receiving news that exogenous

\footnotetext{
${ }^{3}$ A recent paper by Khan and Tsoukalas (2012) also finds that in a New Keynesian model similar to Schmitt-Grohe and Uribe (2012) model, wage markup news shocks specifically continue to play a significant role explaining hours worked. Their findings suggest that sticky prices framework is not the answer to explain hours movement, so the model would still resort to wage markup news shocks to be able to explain hours.
} 
fundamentals will change in the future, agents change their labor supply today. Therefore, news shocks may generate substantial Pigou cycles, i.e. stronger movements of output before the shock materializes. In that case, news shocks can be more important than the $24 \%$ reported in the baseline estimation.

Consistent with our intuition above, the estimated model with labor adjustment cost fit the second moments of hours much better than the baseline model. As reported in Table 4, the augmented model with labor adjustment cost can explain the persistence of hours as well as the correlation of hours and output. We also calculate log marginal likelihood and find that data strongly prefer the model with labor adjustment cost, where parameter $\phi_{H}$ is significantly different from zero.

Despite the significant improvement in model fit, we find that news shocks still explain about $25 \%$ of output when estimating the augmented model with labor adjustment cost for the same observables including data on expectations, which is consistent with the baseline results. As reported in Column 3 of Table 5, the estimated role of news shocks for consumption, investment and government spending is similar to the baseline model.

An important finding of this exercise is that news shocks explain a smaller fraction of hours compared to the baseline model. In this case, news shocks account for about $33 \%$ of hours fluctuations, compared to $46 \%$ in the baseline model. Nevertheless, the confidence interval of this estimate in the augmented model is slightly large, suggesting that having data on expectations of hours would be helpful in identifying news shocks in this case.

Taken together, these results suggest that the importance of news shocks to hours is sensitive to the specification of the labor market. To further understand how news are important for hours, an interesting extension for our study would be to incorporate unemployment into the model to be able to use data on expectations of unemployment rate to extract the importance of news shocks.

\subsection{Model with nominal rigidities}

In this section, we show that data on expectations are informative about the role of news shocks even when the model includes nominal rigidities, so estimated model with nominal rigidities predicts a similar contribution of news shocks to the aggregate fluctuations.

To this end, we augment the baseline model with Calvo sticky prices and wages. We additionally add three types of shocks: a price markup shock, a persistent interest rate target shock and an identically independent monetary policy shock. Unlike the seven shocks in the baseline model, these 
three shocks do not have any news component. The additional equations of the model are shown in the Appendix.

Similar to the baseline estimation, we estimate the model using Bayesian methods with two cases. The first case is without data on expectations which includes ten observables: the seven observables before and inflation, growth rates of real wage and nominal interest rate:

$\left[\Delta \ln y_{t-1, t}, \Delta \ln c_{t-1, t}, \Delta \ln I_{t-1, t}, \Delta \ln h_{t-1, t}, \Delta \ln T F P_{t-1, t}, \Delta \ln p_{i n v, t-1, t}, \Delta \ln G_{t-1, t}, \pi_{t-1, t}, \Delta \ln W_{t-1, t}, R_{t}\right]$

In the second case with data on expectations, there are 14 observables which include the ten observables above and data of two- and four-quarter ahead expectations of output and inflation.

Our estimation suggests that with data on expectations, the model with nominal rigidities predict that news shocks account for about $28 \%$ of output, which is in the similar range as in the baseline model. As reported in the last column of Table 7, the contribution of news shocks to consumption and investment are similar to the real model. An interesting note is that news now explains only about $14 \%$ of hours growth rate, supporting that the role of news shocks to hours is sensitive.

Furthermore, data on expectations also help to estimate the role of news shocks more precisely. In Figure 10, we again plot the prior distributions as well as the posterior distributions of the shares of the variances of output, consumption, investment, hours and government spending estimated with and without data on expectations. Similar to the baseline model, the precision of the estimates of the role of news increases greatly with the inclusion of data on expectations.

We can explain this result similar to our baseline model, that data on expectations put strong restrictions in the estimation that helps to distinguish news shocks from unanticipated shocks. Although not shown here, we also find that even in the model with nominal rigidities, it is difficult to separate news about demand shocks from unanticipated demand shocks. Therefore, when we add data on expectations into the estimation, the role of news about demand shocks become negligible, demonstrated in Figure 10 which shows that the posterior distributions of the variance decomposition of consumption and government spending are almost the same as the prior without data on expectations. Although, as explained above, data on expectations may not change the inference about news shocks when news shocks generate substantial Pigou cycles, such as when prices are fixed, we find that in our estimation, data on expectations are still helpful in inferring news shocks even in the model with nominal rigidities.

Other results such as the small role of news shocks in explaining short run fluctuations, a negligible 
role of news about demand shocks also hold in the model with nominal rigidities. Overall, we find that our results are robust even when adding nominal rigidities into the model.

\subsection{Imperfect Information and Data on Expectations}

This last section of our robustness section discusses our results in the light of imperfect information. This analysis is important because Coibon and Gorodnichenko (2012) suggest that rational expectation imperfect information models are more appropriate to explain the behavior of data on expectations than rational expectation perfect information models. We provide insights that our results above that news shocks cannot be a major driver of business cycles would still hold in imperfect information setting.

Is it appropriate to use forecast in a perfect information framework? In reality, forecasters do not observe the economy perfectly. For example, quarterly macroeconomic data are released with a lag and subject to many revisions. Thus, using data on expectations in a perfect information model may not be appropriate. However, as in Del Negro and Eusepi (2012), the importance of expectation formation within these rational expectation perfect information model used in both policy making and academia makes it interesting to see what data on expectations imply about the importance of news shocks. Also, as we have stressed throughout the paper, from the econometrician's point of view, data on expectations contain information that are not available before since forecasters observe more high frequency data than the quarterly data. Also, as anticipated shocks work through expectations, matching the model expectations with the data is helpful to understand the role of news shocks.

To fit data on expectations better, imperfect information may be a more suitable framework than perfect information. As described in our data section, data on expectations contain persistent forecast errors while perfect information models do not generate persistent forecast errors. Therefore, models with imperfect information can fit data on expectations better 4 .

However, even if we introduce imperfect information, the results may not change. To this end, we augment the baseline model with homogeneous imperfect information, i.e. agents have the same imperfect information set. To make our argument simple, we assume that agents observe all shocks perfectly, except for the four-quarter ahead news about future permanent productivity shocks with a

\footnotetext{
${ }^{4}$ Imperfect information models can generate persistent forecast errors. For example, suppose output follows an AR(1) process. Suppose further that agents do not observe output at all, then their forecast of output in each period is zero. Therefore, forecast errors is an $\mathrm{AR}(1)$.
} 
noisy signal, i.e.

$$
s_{t}^{t+4}=\varepsilon_{x, t}^{t+4}+\eta_{t} .
$$

The simplifying assumption is that agents do not get any new update until the shock materializes, then they observe the shock perfectly. We follow the solution method as in Collard et al. (2009) to solve the model. We keep the parameter values the same as the estimates of the baseline model without data on expectations. We then vary the level of noise to news shocks to show intuitively how imperfect information can alter the results. Figure 11 to Figure 13 plot the impulse responses of output growth rate and its four-quarter ahead expectations to a news shock happening in period 1. In Figure 11, we consider the case when the signal is precise where the noise is small, meaning agents perceive in period 1 that there is a news shock. Then output growth rate responds similarly to the perfect information case, i.e. output increases from today. Since agents can precisely perceive the news, the responses of their expectations are the same as the responses of output growth rate from period 5. In other words, the role of news shocks when noise is small is the same as when the agents have perfect information. We consider a more noisy signal, when the standard deviation of noise is the same as the standard deviation of news in Figure 12. Agents in this case are not sure if there is news or not, implying that their expectations from period 1 to 5 are not the same as actual movements of output growth rate from period 5 to 9 . In other words, expectations move less and output does not change so much from before agents observe the shock, i.e. there is no strong Pigou cycle. Figure 13 is an extreme case when agents do not perceive news shock happens as the signal is very noisy. In this case, expectations do not move much, and as a result, output growth rate does not change until the shock materializes in period 5. In other words, in noisy signal setting, the fact that expectations do not move much leads agents not to change their behavior until they observe the shock. Therefore, the effect of news shocks in short run fluctuations is negligible, and news cannot generate strong Pigou cycles. Especially in the very noisy signal situation, since agents do not change their expectations, news only matter when the shock materializes, so there is no good way to distinguish between news and unanticipated shocks. With this simple experiment, we demonstrate that news shocks cannot be a major source of business cycles even in an imperfect information setting. 


\section{Conclusion}

In this paper, we use data on expectations to investigate the role of news shocks in business cycles. This identification strategy exploits the fact that only through changes in expectations can news shocks affect agents' behaviors before actual shock materializes. We find a robust result that news shocks explain about 24\% of output fluctuations in the U.S. between 1955Q1 and 2006Q4 when the model is estimated with data on expectations. This result is about half of that estimated without data on expectations. Furthermore, the precision of this estimate also improves when we use data on expectations in our estimation. The estimated contribution of news shocks to explaining short run fluctuations is even smaller, explaining about $10 \%$ of output for horizons up to two years before actual shocks materialize. These results arise because data on expectations show that changes in expectations are not large and do not resemble realized output. Therefore, news shocks cannot be main driver of business cycles when we take into account the movements of data on expectations. Additionally, our historical variance decomposition indicates that news shocks are not important in past business cycles in our sample except for the 1980 recession and 1993-94 boom, consistent with data on expectations. In other words, data on expectations are informative about the role of news shocks in business cycles.

An interesting future work to understand further how news shocks are important for aggregate fluctuations is to use data on expectations in models with imperfect information setting. We have demonstrated in models with imperfect information that if agents do not react to news until they actually observe the shock, news shocks do not generate Pigou cycles, and it is difficult to distinguish between unanticipated shocks and news shocks in that case. Nevertheless, it remains to be explored if news shocks can be important in an estimated imperfect information model. Furthermore, in those imperfect information models, data on expectations can also be informative about the role of noise shocks since noise shocks also work through expectations. We believe it an exciting research venue to exploit data on expectations in understanding expectation-driven business cycles.

\section{References}

An, S., And F. SchorfheIde (2007): "Bayesian Analysis of DSGE Models," Econometric Reviews, $26(2-4), 113-172$. 
Ang, A., G. BekAert, And M. Wei (2007): "Do macro variables, asset markets, or surveys forecast inflation better?," Journal of Monetary Economics, 54(4), 1163-1212.

BARsky, R. B., And E. R. Sims (2011): "News shocks and business cycles," Journal of Monetary Economics, 58(3), 273-289.

Barsky, R. B., And E. R. Sims (2012): "Information, Animal Spirits, and the Meaning of Innovations in Consumer Confidence," American Economic Review, 102(4), 1343-1377.

Beaudry, P., And F. Portier (2006): "Stock prices, news and economic fluctuations," American Economic Review, 96(4), 1293-1307.

Blanchard, O., J. L'Huillier, and G. Lorenzoni (2009): "News, noise, and fluctuations: An empirical exploration," (July).

Christiano, L., M. Eichenbaum, and C. Evans (2005): "Nominal rigidities and the dynamic effects of a shock to monetary policy," Journal of Political Economy, 113(1), 1-45.

Coibion, O., and Y. Gorodnichenko (2012a): "Information rigidity and the expectations formation process: A simple framework and new facts," NBER Working Paper.

(2012b): "What Can Survey Forecasts Tell Us About Informational Rigidities?," Journal of Political Economy, 1(120), 116-159.

Davis, J. M. (2007): "News and the Term Structure in General Equilibrium," pp. 1-46.

Del Negro, M., And S. Eusepi (2011): "Fitting observed inflation expectations," Journal of Economic Dynamics and Control, 35(12), 2105-2131.

Del Negro, M., And F. Schorfheide (2012): "DSGE model-based forecasting," .

Forni, M., L. Gambetti, and L. Sala (2011): "No news in business cycles," Economic Journal, forthcoming.

Fujiwara, I., Y. Hirose, And M. Shintani (2011): "Can News Be a Major Source of Aggregate Fluctuations? A Bayesian DSGE Approach," Journal of Money, Credit and Banking, 43(1), 1-29.

Görtz, C., And J. Tsoukalas (2013): "Sector Specific News Shocks in Aggregate and Sectoral Fluctuations," . 
Greenwood, J., Z. Hercowitz, and G. Huffman (1988): "Investment, Capacity Utilization and the Real business cycle," The American Economic Review, 78(3), 402-417.

HaArio, H., E. Saksman, and J. Tamminen (2001): "An Adaptive Metropolis Algorithm," Bernoulli, 7(2), 223-242.

Herbst, E., F. Schorfheide, And N. CEPR (2012): "Sequential Monte Carlo Sampling for DSGE Models," .

Hirose, Y., And T. Kurozumi (2012): "Identifying News Shocks with Forecast Data," mimeo.

Jaimovich, N., And S. Rebelo (2009): "Can news about the future drive the business cycle?," American Economic Review, 99(4), 1097-1118.

Justiniano, A., G. E. Primiceri, and A. Tambalotti (2011): "Investment shocks and the relative price of investment," Review of Economic Dynamics, 14(1), 102-121.

Khan, H., and J. Tsoukalas (2012): "The Quantitative Importance of News Shocks in Estimated DSGE Models," Journal of Money, Credit and Banking, 44(8), 1535-1561.

King, R. G., C. I. Plosser, and S. T. Rebelo (1988): "Production, growth and business cycles: I. The basic neoclassical model," Journal of Monetary Economics, 21(23), 195 - 232.

Milani, F. (2011): "Expectation Shocks and Learning as Drivers of the Business Cycle*," The Economic Journal, 121, 379-401.

Milani, F., And A. Rajbhandari (2012): "Observed Expectations, News Shocks, and the Business Cycle," mimeo.

Ramey, V. A. (2011): "Identifying Government Spending Shocks: It's all in the Timing," The Quarterly Journal of Economics, 126(1), 1-50.

Schmitt-Grohé, S., And M. URIBe (2012): "What's news in business cycles," Econometrica, 80(6), $2733-2764$.

Smets, F., And R. Wouters (2007): "Shocks and frictions in US business cycles: A Bayesian DSGE approach," American Economic Review, 97(3), 586-606. 
Walker, T. B., And E. M. Leeper (2011): "Information flows and news driven business cycles," Review of Economic Dynamics, 14(1), 55-71.

Zarnowitz, V., And P. Braun (1993): "Twenty-two years of the NBER-ASA quarterly economic outlook surveys: Aspects and comparisons of forecasting performance," Business cycles, indicators and forecasting, (January).

ZeEv, N. B., And H. Khan (2012): "Investment-specific news shocks and US business cycles," Manuscript, Carleton University.

\section{Appendix A Main Figures and Tables}

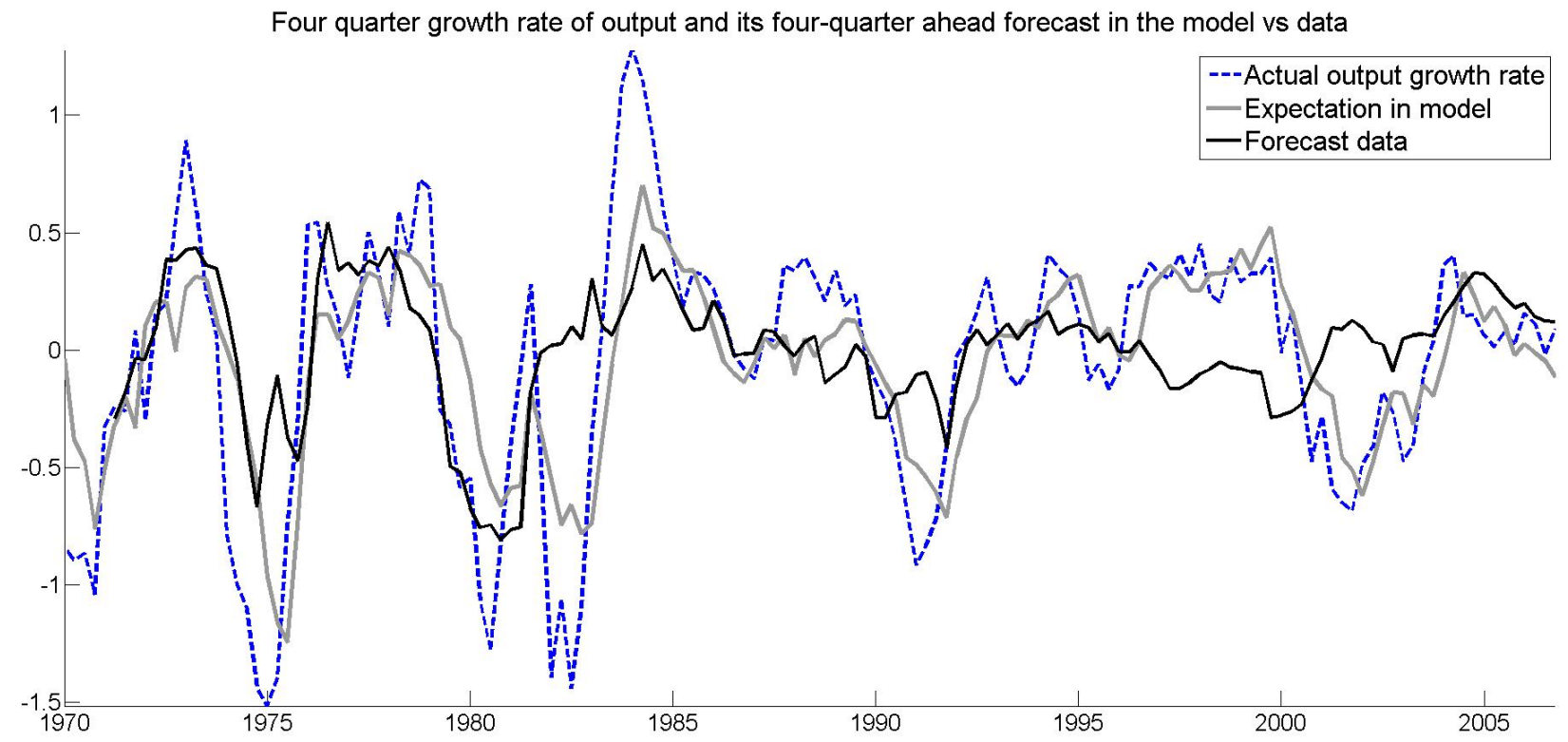

Figure 1: Four quarter output growth rate data with expectation implied in Schmitt-Grohe and Uribe (2012) model and forecast data. Blue dotted line is realized output growth rate, red line with plus sign is model-implied expectation 4 quarter ahead, black dashed line is four-quarter ahead data on expectations. 


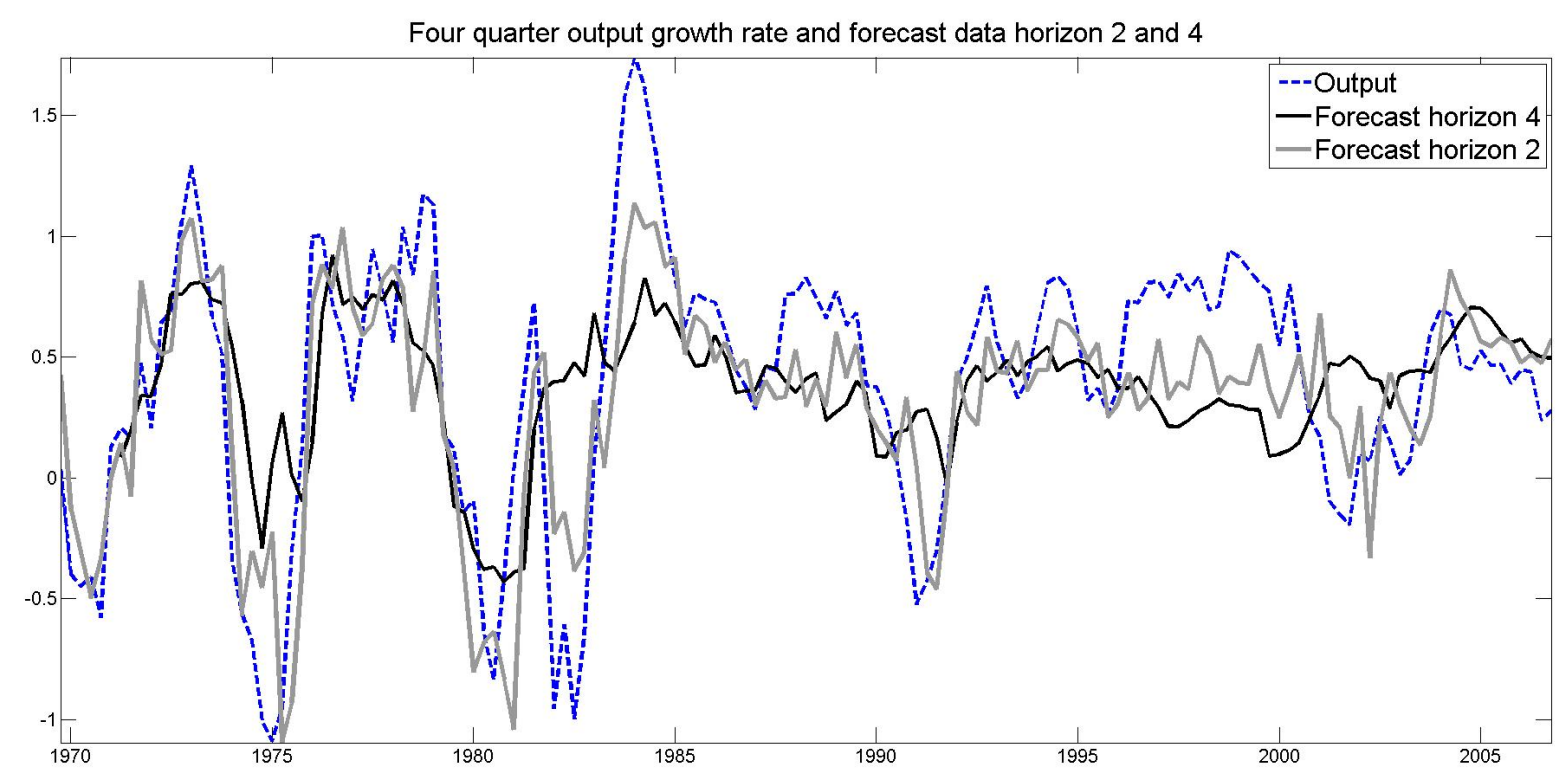

Figure 2: Four quarter growth rate of output: realized and data on expectations at horizon 2 and 4.

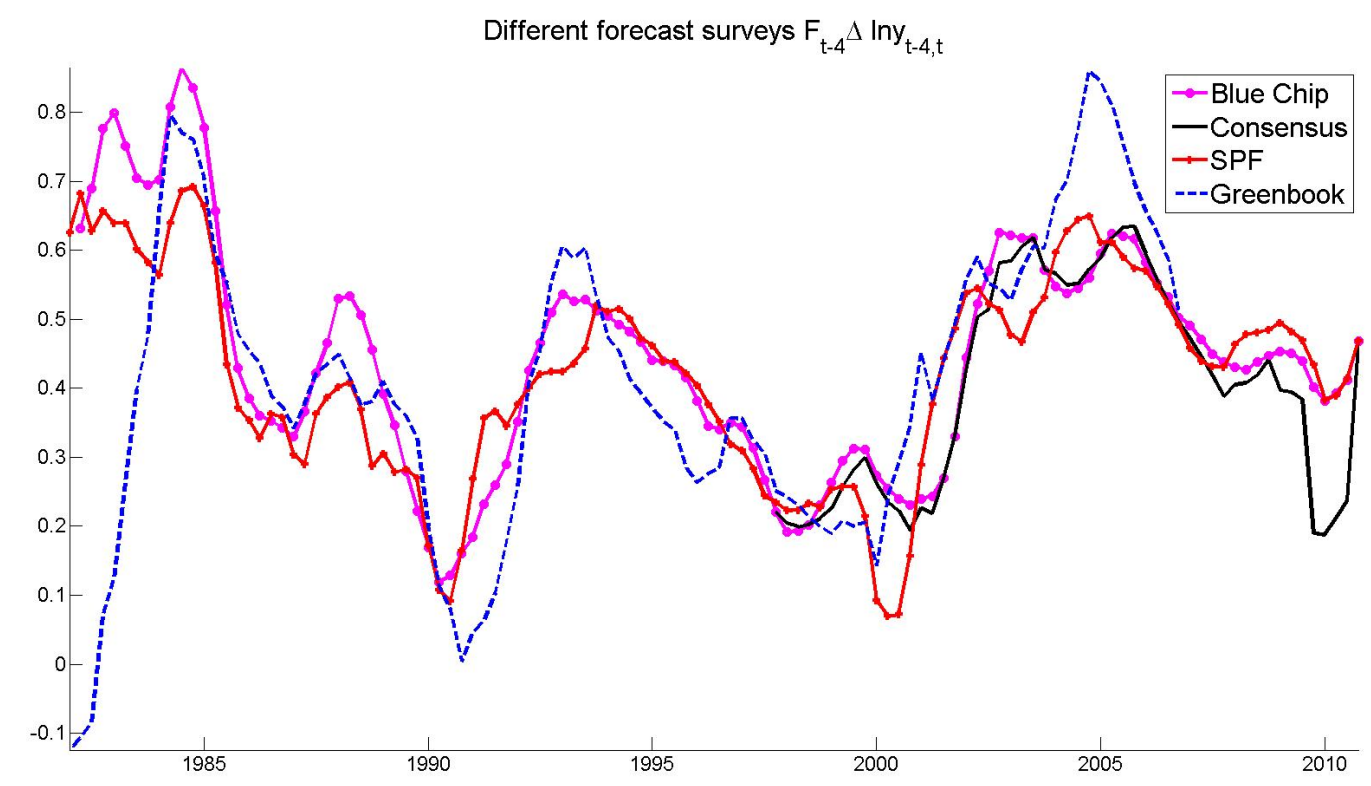

Figure 3: Four quarter output growth rate forecast from different surveys. 

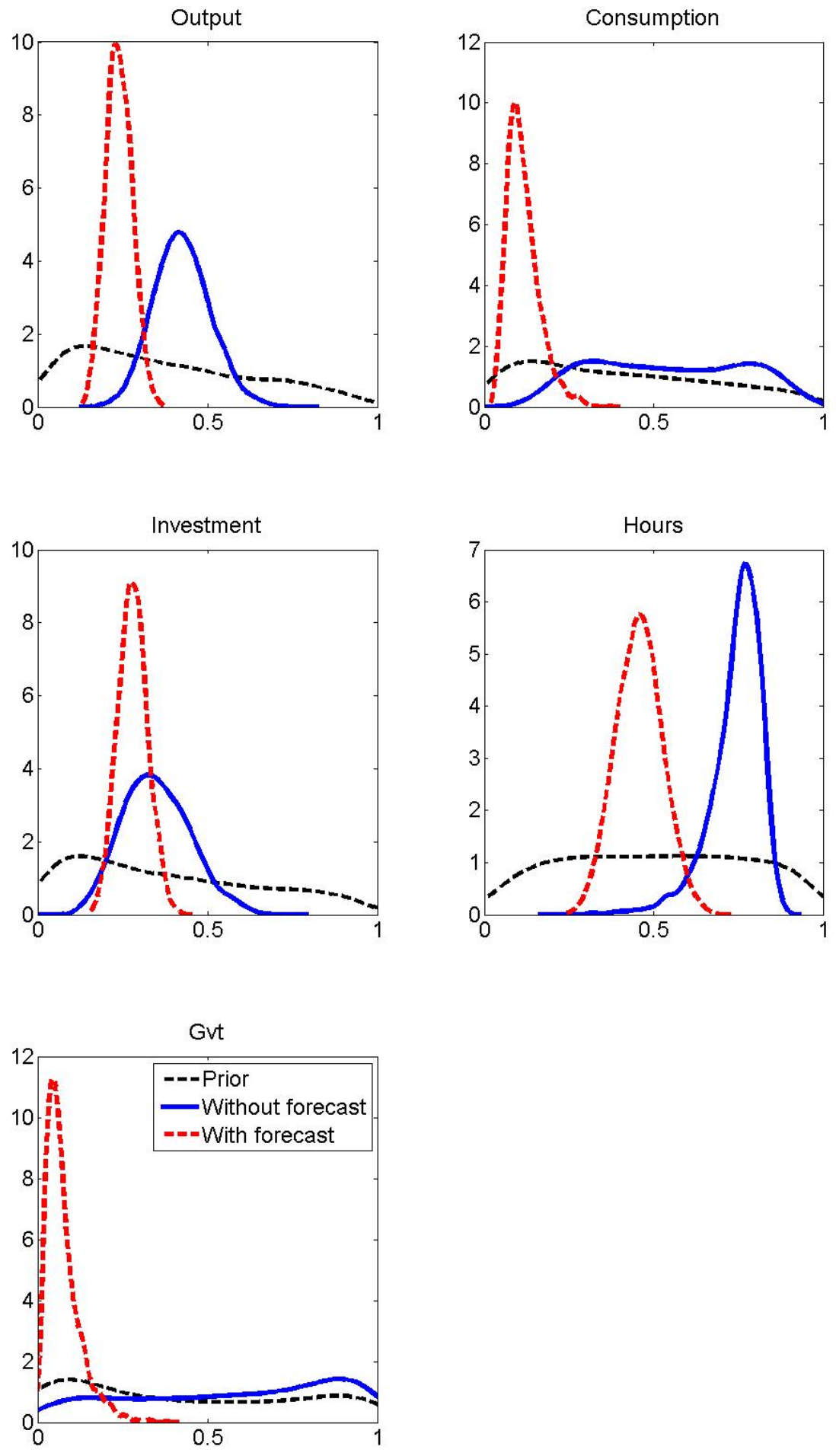

Figure 4: Posterior distribution of the shares of the variances of output, consumption, investment, hours and government spending growth rates due to news with and without forecast. 


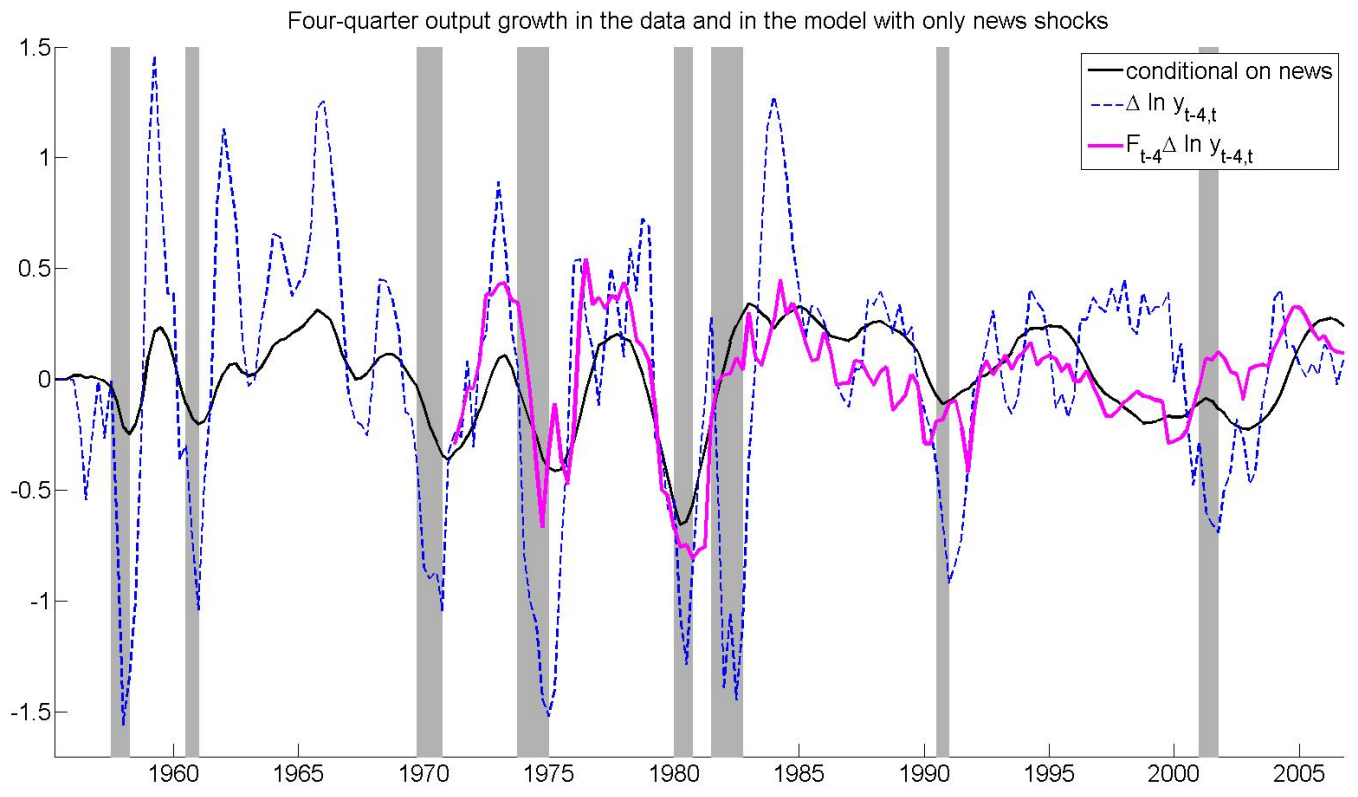

Figure 5: Four quarter output growth rate in the data (the dashed blue line) and in the model with only news shocks (the black line) and forecast data (the pink line).
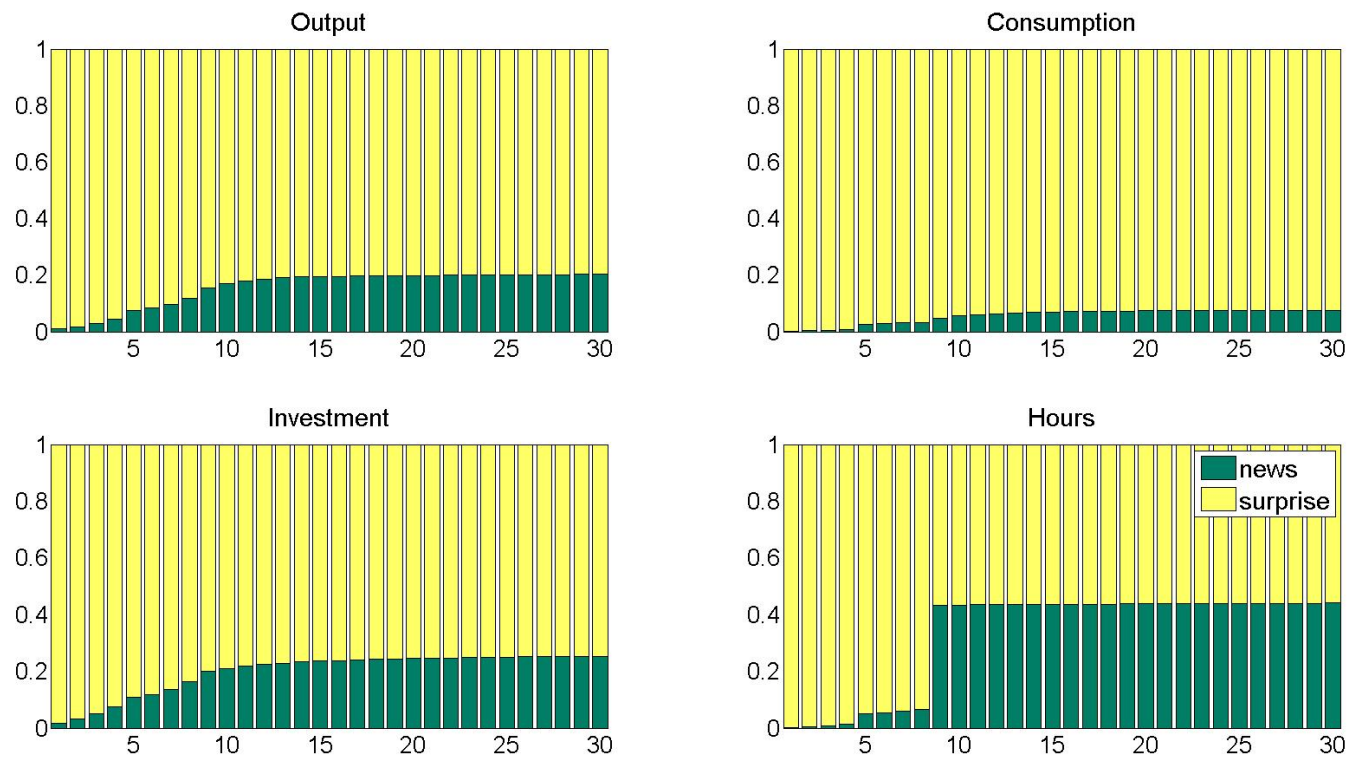

Figure 6: Forecast error variance decomposition 
IR to nonstationary TFP surprise shock

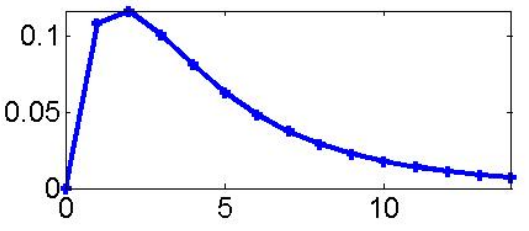

IR to nonstationary IST shock

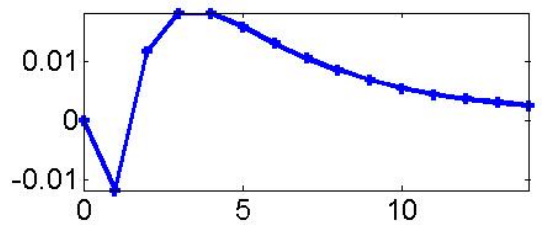

IR to surprise wage markup shock

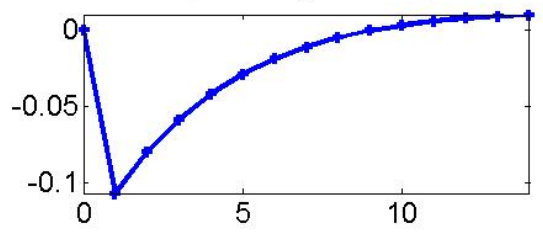

IR to surprise preference shock

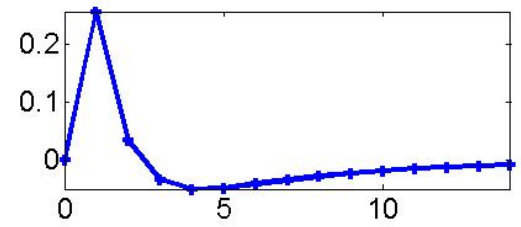

IR to surprise gvt spending shock

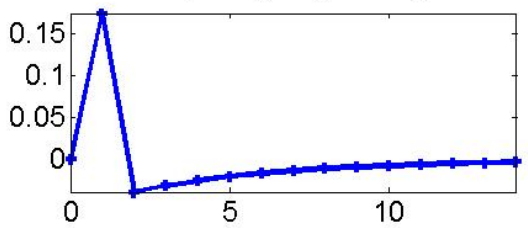

IR to surprise stationary TFP shock

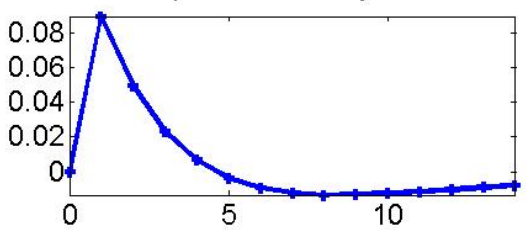

IR to surprise stationary IST shock

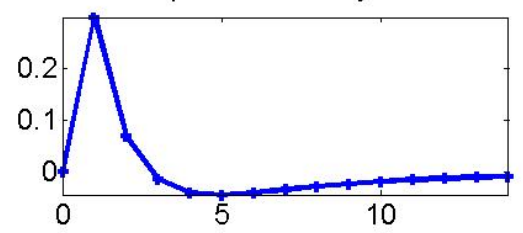

IR to nonstationary TFP news shock

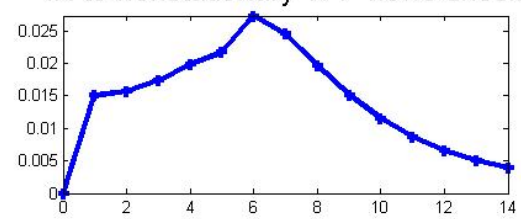

IR, fo nonstationary IST news shock

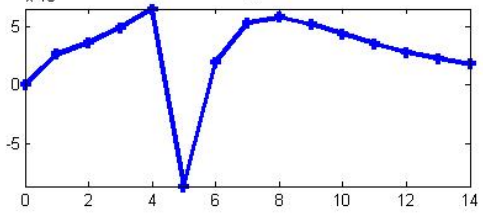

$x^{19} 10^{\text {to }}$ news wage markup shock

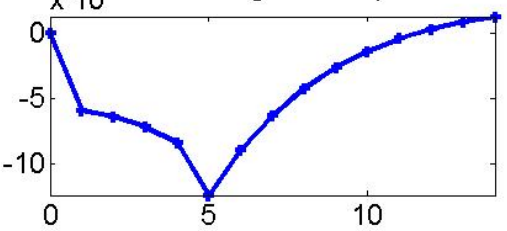

IR to news preference shock

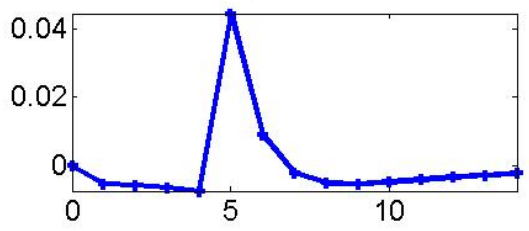

IR to news grt spending shock

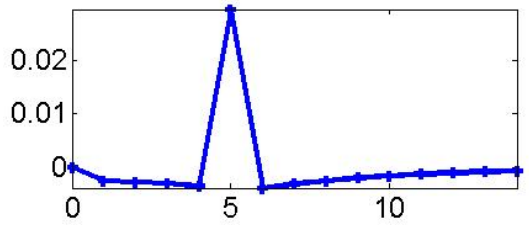

JR to news stationary TFP shock

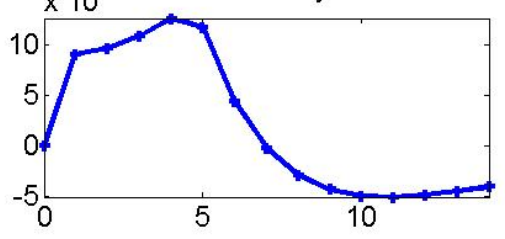

IR to news stationary IST shock

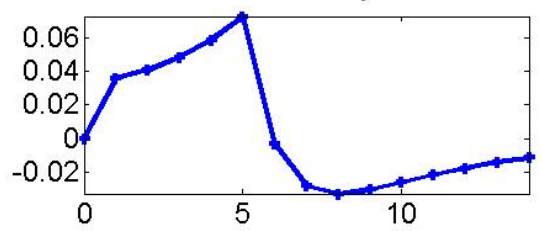

Figure 7: Impulse responses of output growth rate $\Delta \ln y_{t}$ to unanticipated and 4-period ahead news shocks. 


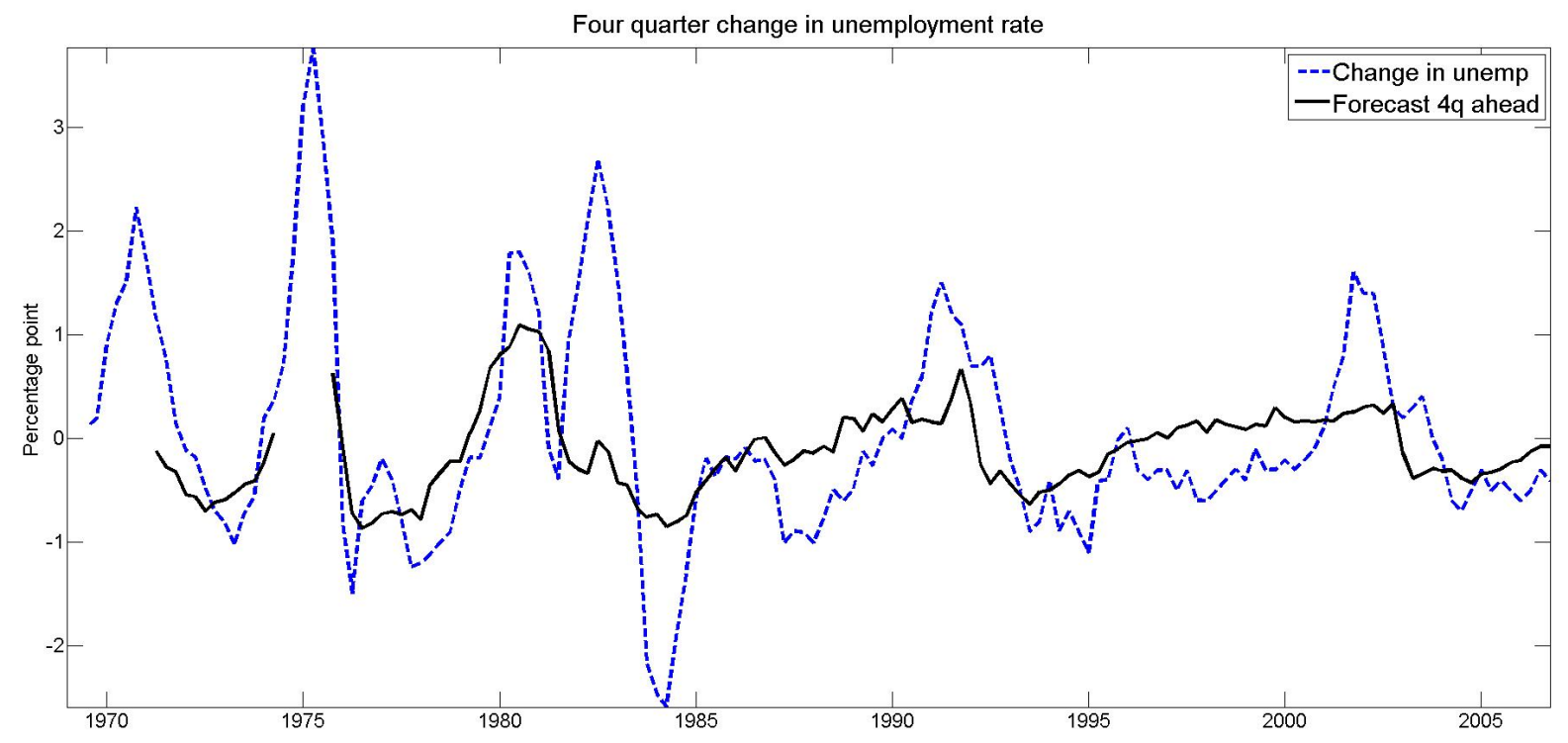

Figure 8: Realized unemployment rate change and the corresponding four-quarter ahead forecast.

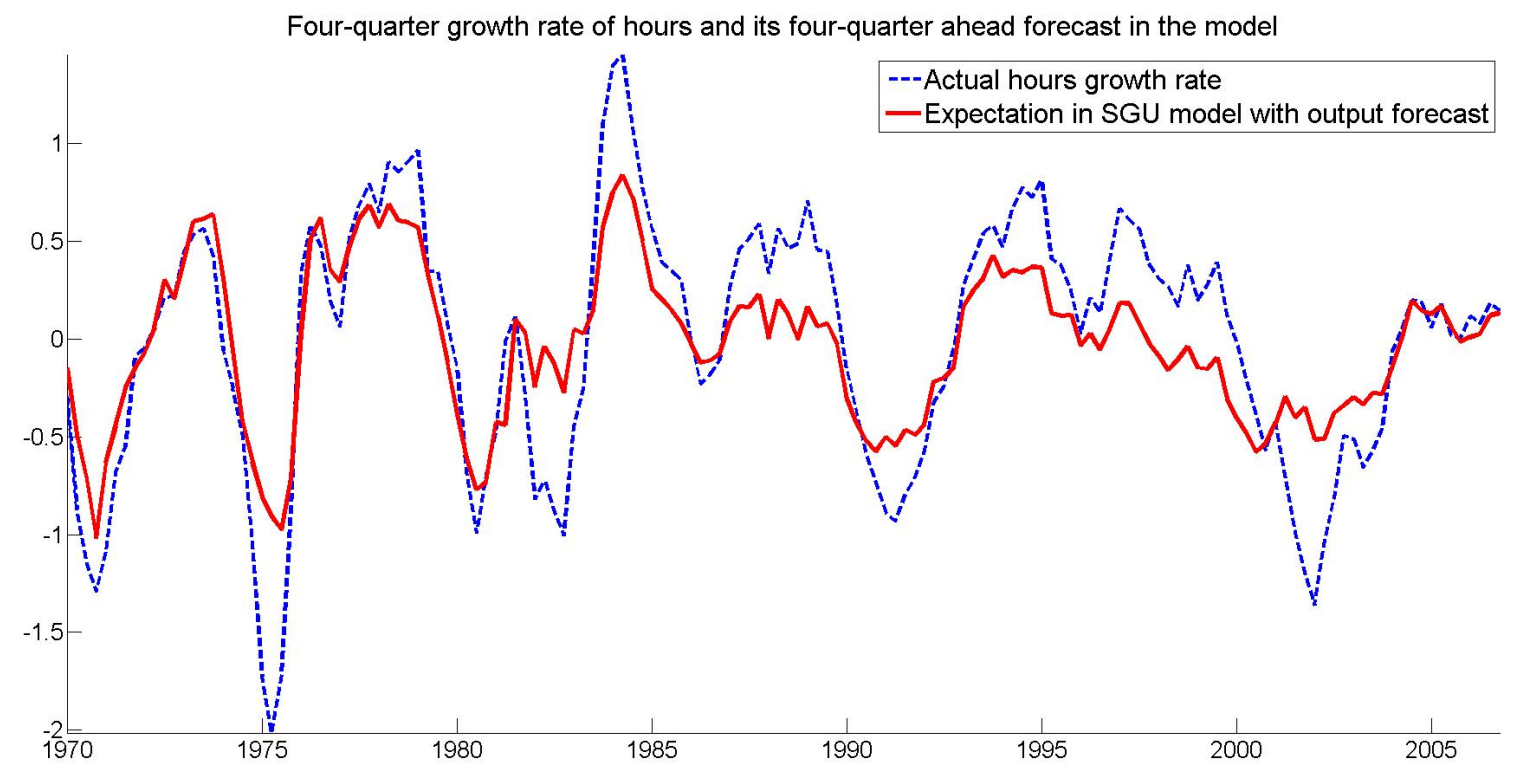

Figure 9: Four-quarter hours growth rate and the four-quarter ahead expectation implied by the SGU model estimated with output forecast. The model-implied expectations are calculated using the median of the posterior distribution of the parameters. 

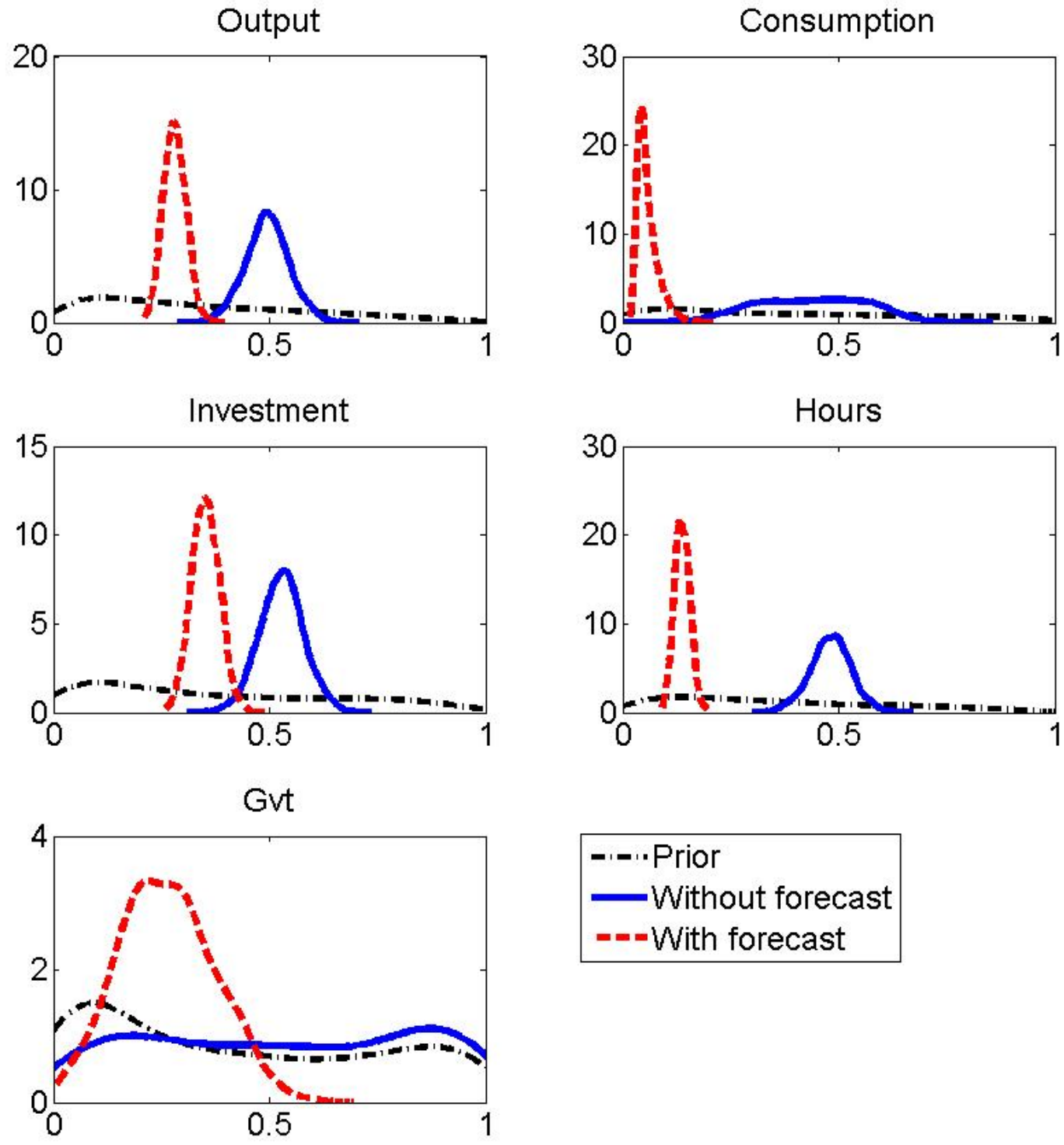

Figure 10: Posterior distribution of the shares of the variances of output, consumption, investment, hours and government spending growth rates due to news with and without forecast in the model with nominal rigidities. 

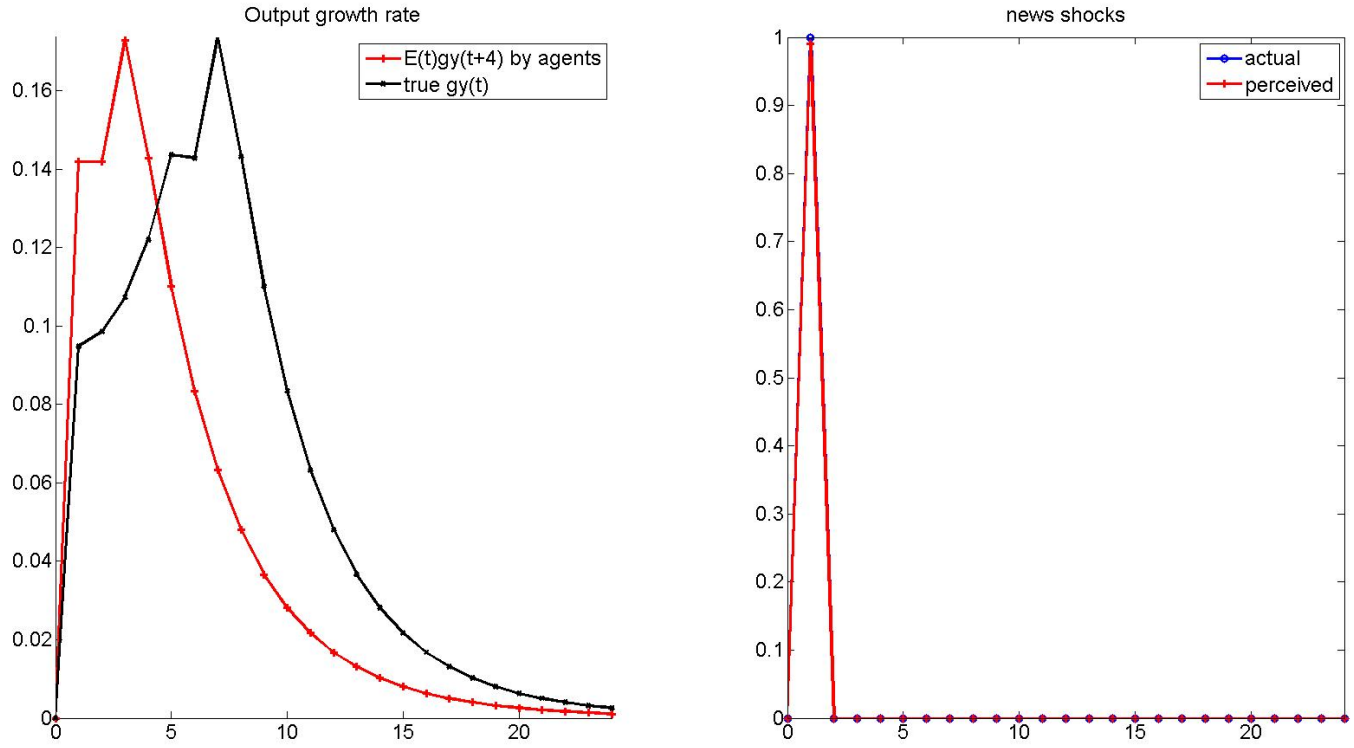

Figure 11: Impulse responses of output growth rate and four-quarter ahead expectations (left panel) to a four-quarter ahead TFP news shock received with $\sigma_{\text {noise }}=0.01 \sigma_{\text {news }}$.
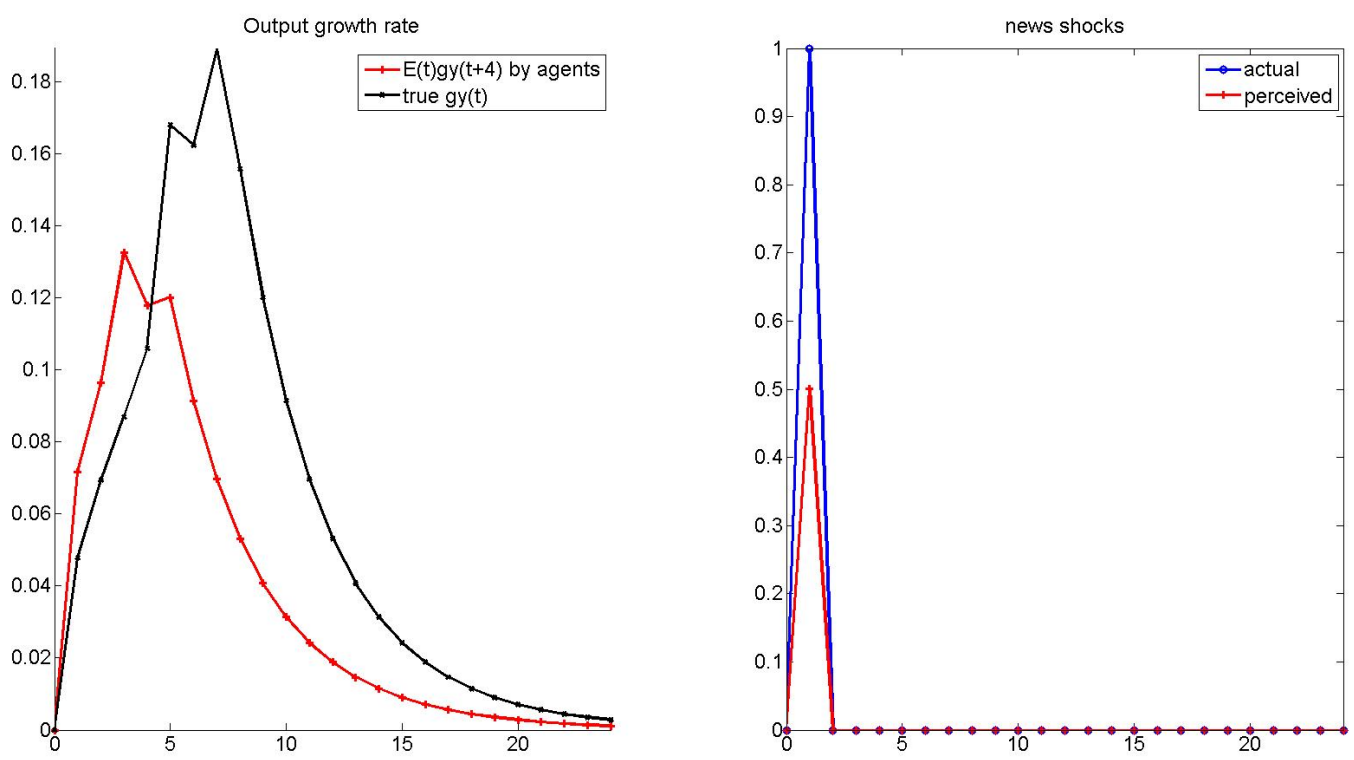

Figure 12: Impulse responses of output growth rate and four-quarter ahead expectations (left panel) to a four-quarter ahead TFP news shock received with $\sigma_{\text {noise }}=\sigma_{\text {news }}$. 

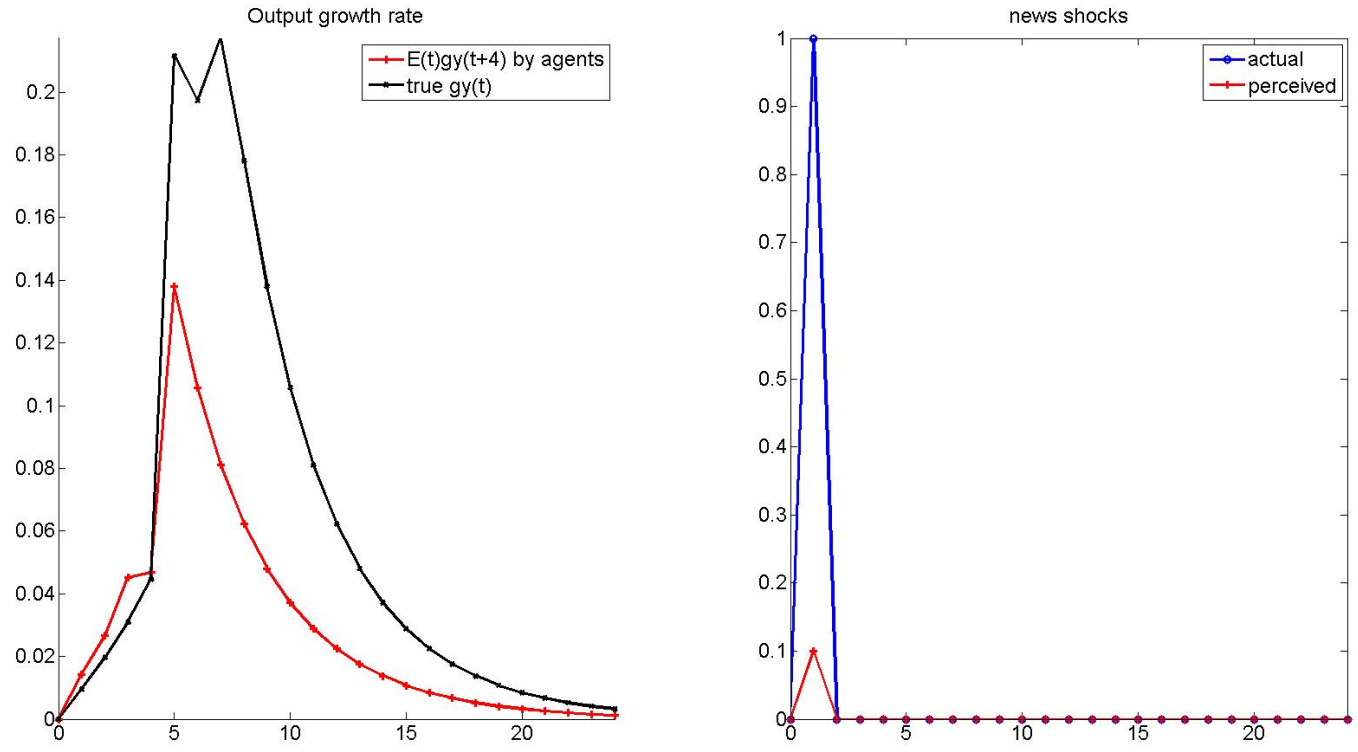

Figure 13: Impulse responses of output growth rate and four-quarter ahead expectations (left panel) to a four-quarter ahead TFP news shock received with $\sigma_{\text {noise }}=3 \sigma_{\text {news }}$. 


\begin{tabular}{|c|c|c|c|c|c|}
\hline & Nowcast & Horizon 1 & Horizon 2 & Horizon 3 & Horizon 4 \\
\hline \multicolumn{6}{|l|}{ Standard deviation: $\sigma_{\text {forecast }} / \sigma_{\text {realized }}$} \\
\hline$\Delta \ln y_{t}$ & 0.56 & 0.38 & 0.29 & 0.25 & 0.25 \\
\hline$\Delta \ln c_{t}$ & 0.51 & 0.33 & 0.25 & 0.23 & 0.21 \\
\hline$\Delta \ln I_{t}$ & 0.59 & 0.39 & 0.27 & 0.23 & 0.22 \\
\hline \multicolumn{6}{|l|}{ Correlation with Output growth rate } \\
\hline$\Delta \ln y_{t}$ & 0.71 & 0.46 & 0.33 & 0.12 & 0.08 \\
\hline$\Delta \ln c_{t}$ & 0.60 & 0.41 & 0.22 & -0.06 & -0.01 \\
\hline$\Delta \ln I_{t}$ & 0.59 & 0.44 & 0.30 & 0.11 & 0.03 \\
\hline \multicolumn{6}{|l|}{ Autocorrelation } \\
\hline$\Delta \ln y_{t}$ & 0.67 & 0.67 & 0.69 & 0.74 & 0.75 \\
\hline$\Delta \ln c_{t}$ & 0.54 & 0.68 & 0.63 & 0.53 & 0.71 \\
\hline$\Delta \ln I_{t}$ & 0.82 & 0.80 & 0.78 & 0.77 & 0.76 \\
\hline \multicolumn{6}{|l|}{ Autocorrelation of forecast error } \\
\hline$\Delta \ln y_{t}$ & -0.05 & 0.04 & 0.13 & $0.20^{*}$ & $0.29^{*}$ \\
\hline$\Delta \ln c_{t}$ & 0.11 & 0.04 & 0.12 & 0.16 & 0.18 \\
\hline$\Delta \ln I_{t}$ & $0.24^{*}$ & $0.37^{*}$ & $0.50^{*}$ & $0.49^{*}$ & $0.47^{*}$ \\
\hline
\end{tabular}

Table 1: Second moments of SPF data for quarterly output, consumption and investment growth rates between 1970Q4 and 2010Q4

Note: a star next to the autocorrelation of forecast error means it is significant at $5 \%$ confidence level. 


\begin{tabular}{llc}
\hline \hline & \multicolumn{1}{c}{ Parameter } & Value \\
\hline$\delta_{0}$ & depreciation rate & 0.025 \\
$\beta$ & discount factor & 0.99 \\
$\alpha_{k}$ & capital share & 0.225 \\
$\alpha_{h}$ & labor share & 0.675 \\
$h$ & steady state hours & 0.2 \\
$g s s$ & steady state share of government spending in output & 0.2 \\
$\mu_{z i}$ & steady state gross growth rate of price of investment & 1.01 \\
$\mu_{y}$ & steady state gross per capital GDP growth rate & 1.0045 \\
$\eta_{w s s}$ & steady state wage markup & 1.15 \\
\hline \hline
\end{tabular}

Table 2: Calibrated parameters 


\begin{tabular}{|c|c|c|c|c|c|c|c|c|c|}
\hline \multirow[t]{2}{*}{ Parameters } & \multicolumn{3}{|c|}{ Priors } & \multicolumn{3}{|c|}{ Posterior without forecast } & \multicolumn{3}{|c|}{ Posterior with forecast } \\
\hline & Distribution & Mean & Std & median & $5 \%$ & $95 \%$ & median & $5 \%$ & $95 \%$ \\
\hline$v$ & $\mathrm{G}$ & 4 & 1 & 4.11 & 3.21 & 5.16 & 4.79 & 3.74 & 6.05 \\
\hline$\gamma$ & $\mathrm{U}$ & 0.5 & 0.29 & 0.00 & 0.00 & 0.01 & 0.00 & 0.00 & 0.00 \\
\hline$\delta_{2} / \delta_{1}$ & IG & 1 & 1 & 0.36 & 0.24 & 0.52 & 0.39 & 0.25 & 0.56 \\
\hline$s$ & G & 4 & 1 & 9.22 & 7.41 & 11.34 & 8.84 & 7.10 & 10.89 \\
\hline$\kappa$ & B & 0.5 & 0.2 & 0.90 & 0.87 & 0.92 & 0.94 & 0.92 & 0.96 \\
\hline$\rho_{\mu_{z n}}$ & B & 0.7 & 0.2 & 0.86 & 0.61 & 0.98 & 0.95 & 0.83 & 0.99 \\
\hline$\rho_{\mu_{z i}}$ & B & 0.5 & 0.2 & 0.48 & 0.39 & 0.58 & 0.48 & 0.38 & 0.57 \\
\hline$\rho_{a n}$ & B & 0.7 & 0.2 & 0.92 & 0.84 & 0.96 & 0.75 & 0.64 & 0.85 \\
\hline$\rho_{a i}$ & B & 0.5 & 0.2 & 0.43 & 0.20 & 0.63 & 0.42 & 0.32 & 0.51 \\
\hline$\rho_{g}$ & B & 0.7 & 0.2 & 0.96 & 0.93 & 0.99 & 0.97 & 0.95 & 0.99 \\
\hline$\rho_{b}$ & B & 0.5 & 0.2 & 0.18 & 0.08 & 0.31 & 0.36 & 0.27 & 0.46 \\
\hline$\rho_{\eta_{w}}$ & B & 0.7 & 0.2 & 0.98 & 0.95 & 1.00 & 0.96 & 0.93 & 0.98 \\
\hline$\rho_{x g}$ & B & 0.7 & 0.2 & 0.73 & 0.44 & 0.89 & 0.66 & 0.37 & 0.85 \\
\hline$\sigma_{\mu_{z n}}^{0}$ & G & 0.45 & 0.45 & 0.38 & 0.19 & 0.56 & 0.33 & 0.26 & 0.42 \\
\hline$\sigma_{\mu_{z i}}^{0}$ & G & 0.31 & 0.31 & 0.20 & 0.03 & 0.34 & 0.25 & 0.05 & 0.35 \\
\hline$\sigma_{a^{n}}^{\mu_{z i}}$ & G & 1.5 & 1.5 & 0.65 & 0.53 & 0.74 & 0.64 & 0.52 & 0.73 \\
\hline$\sigma_{a^{i}}$ & G & 17.15 & 17.15 & 12.10 & 8.94 & 15.86 & 12.86 & 9.97 & 16.51 \\
\hline$\sigma_{g}$ & G & 1.05 & 1.05 & 0.66 & 0.09 & 1.07 & 1.07 & 0.97 & 1.18 \\
\hline$\sigma_{b}$ & G & 6.3 & 6.3 & 3.95 & 0.73 & 6.54 & 11.30 & 7.28 & 18.00 \\
\hline$\sigma_{\eta_{w}}$ & G & 1.19 & 1.19 & 0.84 & 0.10 & 2.58 & 3.58 & 2.60 & 4.67 \\
\hline$\sigma_{\mu_{z n}}^{4}$ & $\mathrm{G}$ & 0.19 & 0.19 & 0.09 & 0.01 & 0.28 & 0.10 & 0.01 & 0.26 \\
\hline $\begin{array}{l}\mu_{z n} \\
\sigma_{\mu_{z n}}^{8}\end{array}$ & G & 0.19 & 0.19 & 0.11 & 0.01 & 0.29 & 0.20 & 0.04 & 0.35 \\
\hline$\sigma_{\mu_{z i}}^{4 z n}$ & G & 0.13 & 0.13 & 0.16 & 0.02 & 0.34 & 0.08 & 0.01 & 0.24 \\
\hline$\sigma_{\mu_{z i}}^{8}$ & G & 0.13 & 0.13 & 0.17 & 0.02 & 0.34 & 0.21 & 0.02 & 0.34 \\
\hline$\sigma_{a n}^{4}$ & G & 0.61 & 0.61 & 0.12 & 0.02 & 0.33 & 0.13 & 0.02 & 0.32 \\
\hline$\sigma_{a n}^{8}$ & G & 0.61 & 0.61 & 0.11 & 0.01 & 0.30 & 0.15 & 0.02 & 0.41 \\
\hline$\sigma_{a i}^{4}$ & G & 7 & 7 & 2.55 & 0.30 & 7.39 & 4.83 & 1.78 & 7.38 \\
\hline$\sigma_{a i}^{8}$ & G & 7 & 7 & 5.70 & 1.12 & 10.75 & 4.32 & 1.02 & 6.80 \\
\hline$\sigma_{g v t}^{4}$ & G & 0.43 & 0.43 & 0.59 & 0.06 & 1.06 & 0.14 & 0.02 & 0.40 \\
\hline$\sigma_{g v t}^{8}$ & G & 0.43 & 0.43 & 0.35 & 0.04 & 0.96 & 0.11 & 0.01 & 0.31 \\
\hline$\sigma_{\eta_{w}}^{4}$ & $\mathrm{G}$ & 0.49 & 0.49 & 4.74 & 0.31 & 5.81 & 0.45 & 0.04 & 1.73 \\
\hline$\sigma_{\eta_{w}}^{8}$ & G & 0.49 & 0.49 & 0.73 & 0.06 & 5.16 & 4.58 & 3.67 & 5.56 \\
\hline$\sigma_{b}^{4}$ & G & 2.57 & 2.57 & 2.14 & 0.23 & 5.75 & 1.58 & 0.19 & 4.24 \\
\hline$\sigma_{b}^{8}$ & G & 2.57 & 2.57 & 2.16 & 0.22 & 5.92 & 1.10 & 0.13 & 3.16 \\
\hline$m e^{y}$ & $\mathrm{U}$ & 0.14 & 0.08 & 0.29 & 0.29 & 0.29 & 0.29 & 0.29 & 0.29 \\
\hline$m e^{y 2}$ & $\mathrm{U}$ & 0.06 & 0.03 & & & & 0.11 & 0.10 & 0.12 \\
\hline$m e^{y 4}$ & $\mathrm{U}$ & 0.04 & 0.02 & & & & 0.01 & 0.00 & 0.03 \\
\hline
\end{tabular}

Table 3: Estimated Parameters

Note: The estimated parameters are reported at posterior mean of the distribution computed from the last 200,000 draws. 


\begin{tabular}{|c|c|c|c|c|c|}
\hline & $\Delta \ln y_{t, t-1}$ & $\Delta \ln c_{t, t-1}$ & $\Delta \ln I_{t, t-1}$ & $\Delta \ln h_{t, t-1}$ & $\Delta \ln G_{t, t-1}$ \\
\hline \multicolumn{6}{|c|}{ Standard deviation } \\
\hline Data & 0.91 & 0.51 & 2.28 & 0.84 & 1.15 \\
\hline $\mathrm{W} / \mathrm{o}$ forecast & 0.65 & 0.75 & 2.67 & 0.83 & 1.13 \\
\hline $\mathrm{W} /$ forecast & 0.63 & 0.58 & 2.75 & 0.88 & 1.15 \\
\hline $\mathrm{W} / \mathrm{LAC} \mathrm{w} /$ forecast & 0.64 & 0.61 & 2.78 & 0.76 & 1.13 \\
\hline \multicolumn{6}{|l|}{ Correlation with gy } \\
\hline Data & 1.00 & 0.50 & 0.69 & 0.72 & 0.25 \\
\hline $\mathrm{W} / \mathrm{o}$ forecast & 1.00 & 0.63 & 0.76 & 0.45 & 0.36 \\
\hline $\mathrm{W} /$ forecast & 1.00 & 0.55 & 0.72 & 0.43 & 0.38 \\
\hline $\mathrm{W} / \mathrm{LAC} \mathrm{w} /$ forecast & 1.00 & 0.56 & 0.71 & 0.50 & 0.37 \\
\hline \multicolumn{6}{|l|}{ Autocorrelation } \\
\hline Data & 0.28 & 0.20 & 0.52 & 0.59 & 0.05 \\
\hline $\mathrm{W} / \mathrm{o}$ forecast & 0.49 & 0.37 & 0.59 & 0.13 & 0.02 \\
\hline $\mathrm{W} /$ forecast & 0.49 & 0.43 & 0.56 & 0.06 & 0.03 \\
\hline $\mathrm{W} / \mathrm{LAC} \mathrm{w} /$ forecast & 0.48 & 0.35 & 0.57 & 0.44 & 0.04 \\
\hline
\end{tabular}

Table 4: Model Fit: second moments 


\begin{tabular}{cccc}
\hline \hline Variable & $\begin{array}{c}\text { Without forecast } \\
\text { Baseline model }\end{array}$ & With forecast & With forecast \\
& W/ Labor adj \\
\hline$\Delta \ln y_{t-1, t}$ & 42.2 & 24.2 & 24.7 \\
& $(29.3,56.7)$ & $(18.4,30.5)$ & $(17.8,31.6)$ \\
$\Delta \ln c_{t-1, t}$ & 53.1 & 11.1 & 8.3 \\
& $(21.8,87.3)$ & $(5.80,20.4)$ & $(3.5,15.4)$ \\
$\Delta \ln I_{t-1, t}$ & 34.3 & 28.2 & 30.9 \\
$\Delta \ln h_{t-1, t}$ & $(19.6,52.0)$ & $(21.7,34.9)$ & $(23.1,38.7)$ \\
& $(59.8,83.5)$ & $(35.3,57.6)$ & $(12.2,50.8)$ \\
$\Delta \ln G_{t-1, t}$ & 57.3 & 7.7 & 7.0 \\
& $(6.69,96.0)$ & $(1.96,18.3)$ & $(1.6,17.1)$ \\
\hline \hline
\end{tabular}

Table 5: Contribution of all news shocks

Note: The contribution is reported at posterior mean of the distribution, computed from 200,000 draws. The numbers in parentheses are $5-95 \%$ confidence interval. 


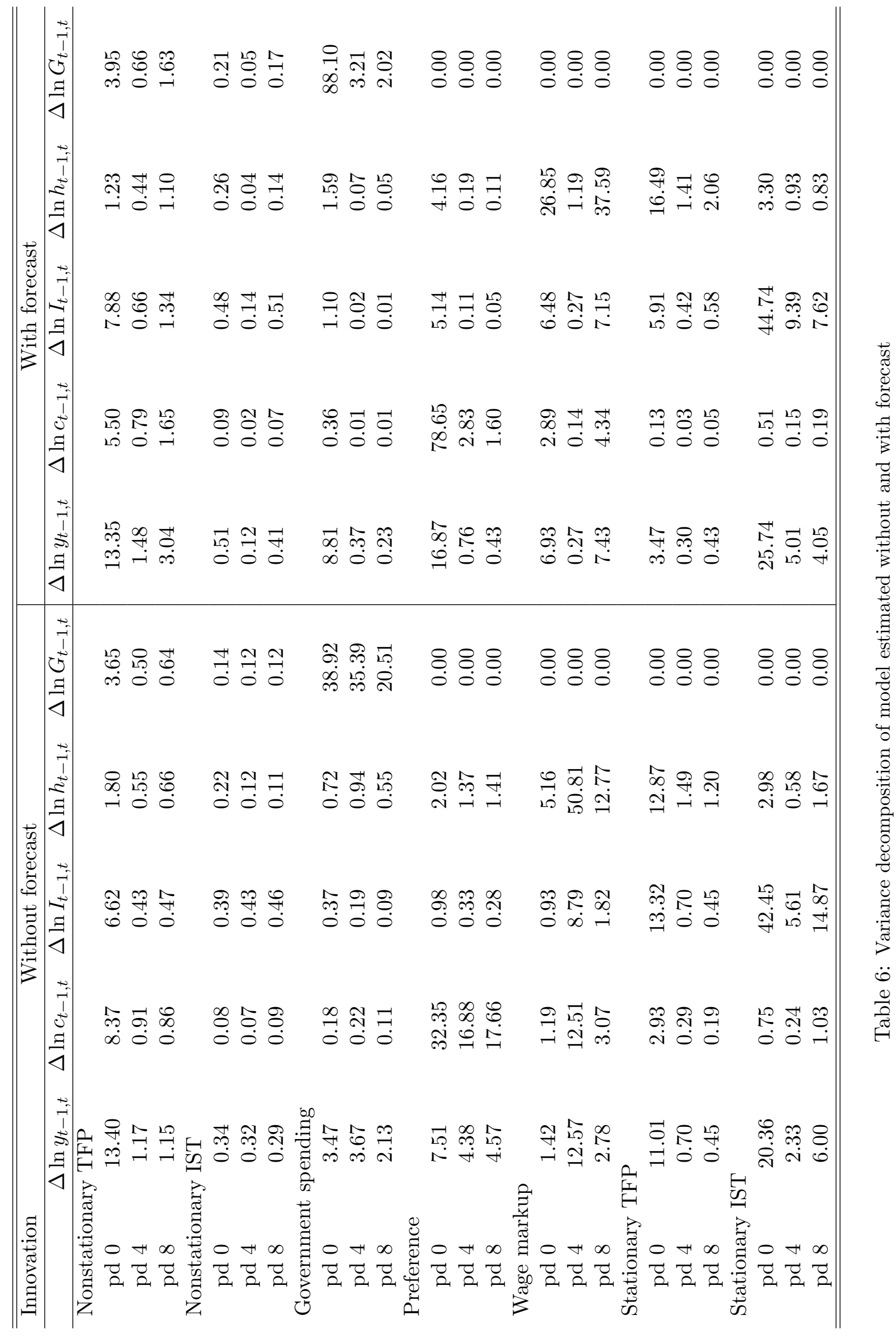




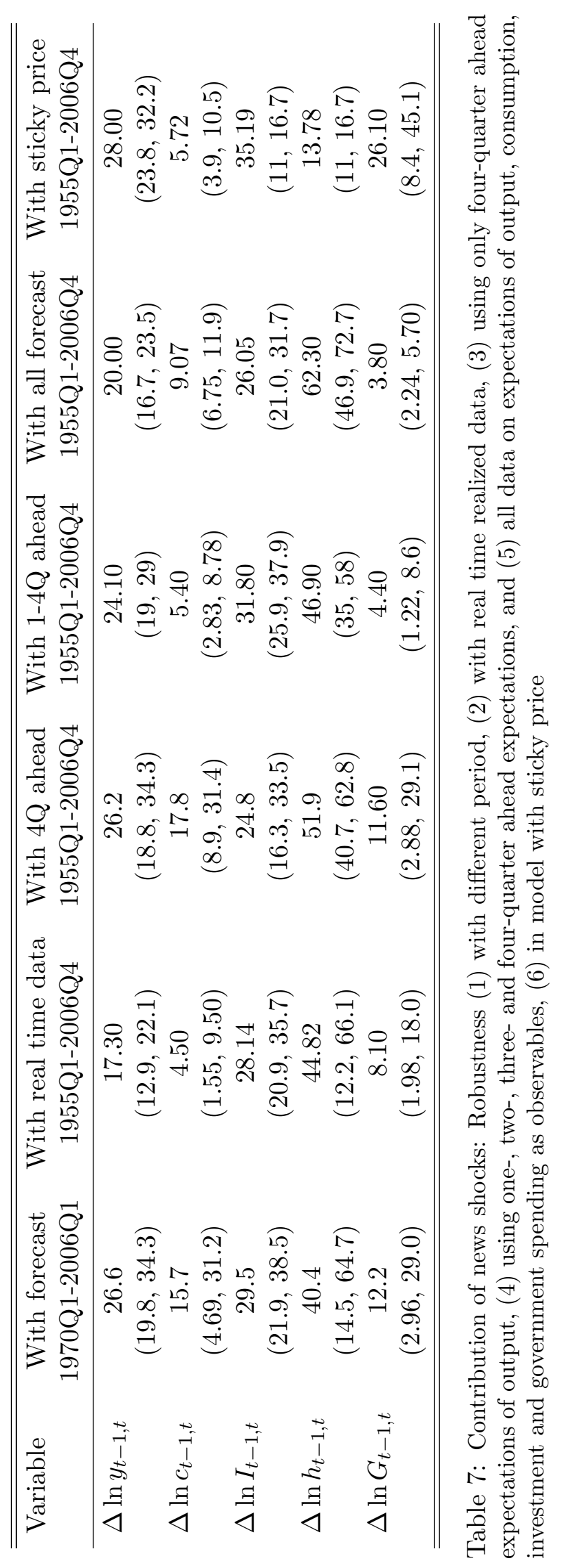




\section{Appendix B Data Appendix}

- Population: smooth out LNU00000000Q

- Real GDP (from NIPA 1.1.6): Real GDP/Population

- Investment: Nominal fixed investment/Population/GDP deflator

- Consumption: Nominal consumption/Population/GDP deflator

- Hours: PRS85006023*Employment (LNS12000000) /100/Population OR PRS85006033/Population

- Wage: nominal wage (PRS85006103)/GDP deflator

- Government spending: Nominal Government spending/Population/GDP deflator

- Interest rate: Tbill from FRB_H15

- Relative investment prices: Fixed investment price deflator/GDP deflator 


\section{Appendix C Basline Model Equilibrium Conditions}

Stationary FOC:

$$
\begin{aligned}
& n_{t}=\left(c_{t}-\kappa \frac{c_{t-1}}{\mu_{t}}\right)^{\gamma} \frac{n_{t-1}^{1-\gamma}}{\mu_{t}^{1-\gamma}} \\
& v_{t}=c_{t}-\kappa \frac{c_{t-1}}{\mu_{t}}-\psi h_{t}^{\nu} n_{t} \\
& b_{t} v_{t}^{-\sigma}-\beta \kappa E_{t} b_{t+1} \frac{1}{\mu_{t+1}^{\sigma}} v_{t+1}^{-\sigma}-\lambda_{3 t} \gamma \frac{n_{t}}{c_{t}-\kappa \frac{c_{t-1}}{\mu_{t}}}+\beta \kappa \gamma E_{t} \frac{1}{\mu_{t+1}^{\sigma}} \lambda_{3 t+1} \frac{n_{t+1}}{c_{t+1}-\frac{\kappa c_{t}}{\mu_{t+1}}}=\lambda_{1 t} \\
& -b_{t} v_{t}^{-\sigma} \psi \nu h_{t}^{\nu-1} n_{t}+\lambda_{1 t} w_{t}^{h}=0 \\
& -b_{t} \psi v_{t}^{-\sigma} h_{t}^{\nu}+\lambda_{3 t}-(1-\gamma) \beta E_{t} \frac{1}{\mu_{t+1}^{\sigma}} \lambda_{3 t+1} \frac{\mu_{t+1} n_{t+1}}{n_{t}}=0 \\
& \lambda_{1, t} \frac{1}{R_{t}}=\beta \lambda_{1, t+1} \mu_{t+1}^{-\sigma} \\
& \lambda_{2, t}=\beta E_{t}\left[\lambda_{1, t+1} \mu_{t+1}^{-\sigma} \frac{z_{t}^{i}}{z_{t+1}^{i}} r_{t+1}^{k} u_{t+1}+\lambda_{2, t+1} \mu_{t+1}^{-\sigma} \frac{z_{t}^{i}}{z_{t+1}^{i}}\left(1-\delta\left(u_{t+1}\right)\right)\right] \\
& \lambda_{1 t} r_{t}^{k}=\lambda_{2 t}\left(\delta_{1}+\delta_{2}\left(u_{t}-1\right)\right) \\
& \lambda_{1, t}=\lambda_{2, t}\left[a_{t}^{i}\left(1-\frac{s}{2}\left(\mu_{t}^{i} \frac{i_{t}}{i_{t-1}}-\mu_{I}\right)^{2}\right)-s a_{t}^{i} \frac{i_{t}}{i_{t-1}} \mu_{t}^{i}\left(\frac{i_{t}}{i_{t-1}} \mu_{t}^{i}-\mu_{I}\right)\right] \\
& +\beta E_{t} \lambda_{2, t+1} \mu_{t+1}^{-\sigma} \frac{z_{t}^{i}}{z_{t+1}^{i}} s a_{t+1}^{i}\left(\frac{i_{t+1}}{i_{t}} \mu_{t+1}^{i}\right)^{2}\left(\frac{i_{t+1}}{i_{t}} \mu_{t+1}^{i}-\mu_{I}\right) \\
& k_{t+1}=\left(1-\delta\left(u_{t}\right)\right) \frac{k_{t}}{\mu_{t}^{i}}+a_{t}^{i} i_{t}\left[1-\frac{s}{2}\left(\frac{i_{t}}{i_{t-1}} \mu_{t}^{i}-\mu_{I}\right)^{2}\right] \\
& r_{t}^{k}=\left(\mu_{t}^{i}\right)^{1-\alpha_{k}} a_{t}^{n} u_{t}^{\alpha_{k}-1} \alpha_{k} k_{t}^{\alpha_{k}-1} h_{t}^{\alpha_{h}} L^{1-\alpha_{k}-\alpha_{h}} \\
& w_{t}=\left(\mu_{t}^{i}\right)^{-\alpha_{k}} a_{t}^{n} u_{t}^{\alpha_{k}} \alpha_{h} k_{t}^{\alpha_{k}} h_{t}^{\alpha_{h}-1} L^{1-\alpha_{k}-\alpha_{h}} \\
& w_{t}^{h}=\frac{w_{t}}{\eta_{w, t}} \\
& y_{t}=c_{t}+\mu_{t}^{g} g_{t}+i_{t} \text { where } \mu_{t}^{g}=\left(\mu_{t-1}^{g}\right)^{\rho_{x g}}\left(\mu_{t}\right)^{-1} \\
& y_{t}=a_{t}^{n}\left(\mu_{t}^{i}\right)^{-\alpha_{k}} u_{t}^{\alpha_{k}} k_{t}^{\alpha_{k}} h_{t}^{\alpha_{h}} L^{1-\alpha_{k}-\alpha_{h}}
\end{aligned}
$$

\section{Appendix D Model with Nominal Rigidities Equilibrium Condi- tions}

Additional conditions: 


\section{Appendix E Extra Figures and Tables}

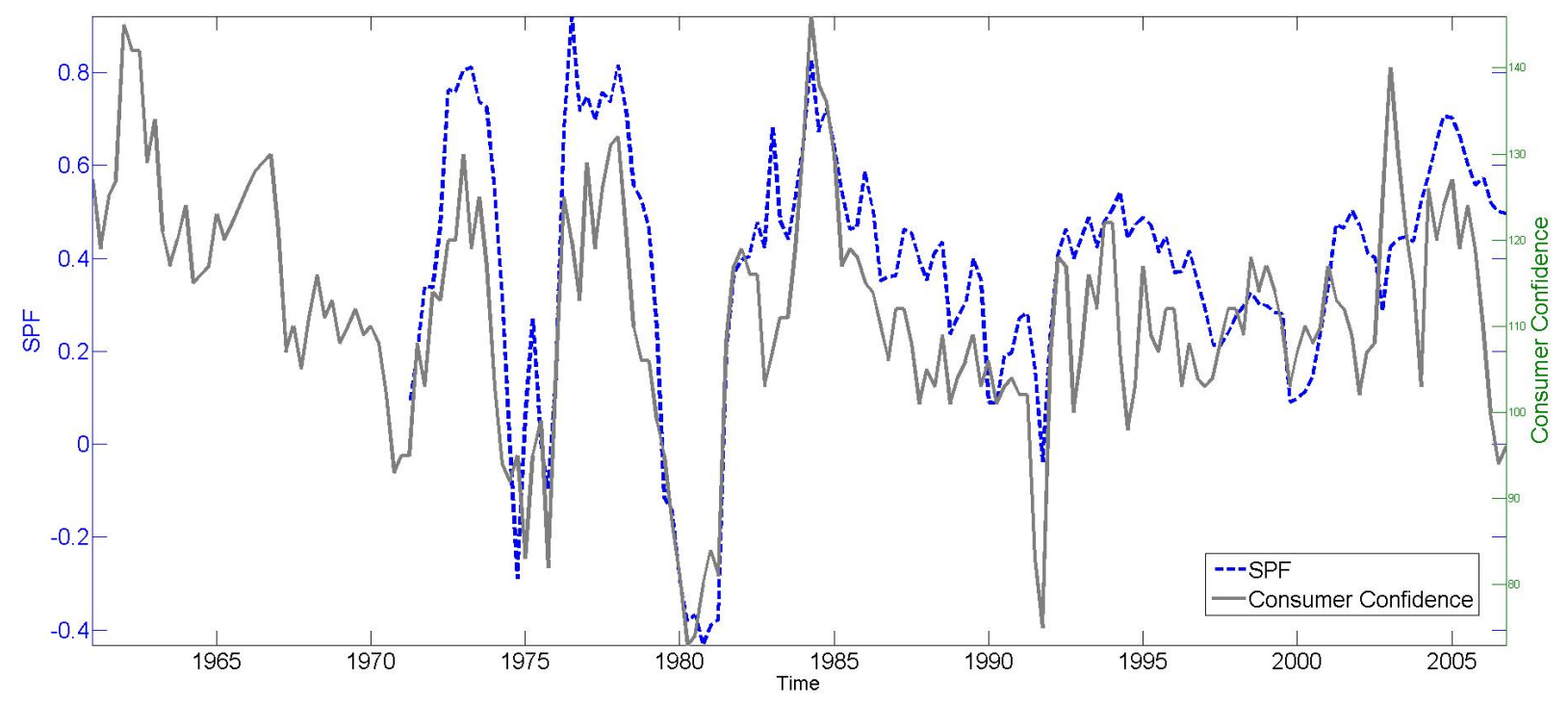

Figure A.1: SPF four-quarter output growth rate forecast a year in advance (blue dashed line) and Expected changes in business conditions in a year from the Michigan survey of Consumer Confidence (gray line). 


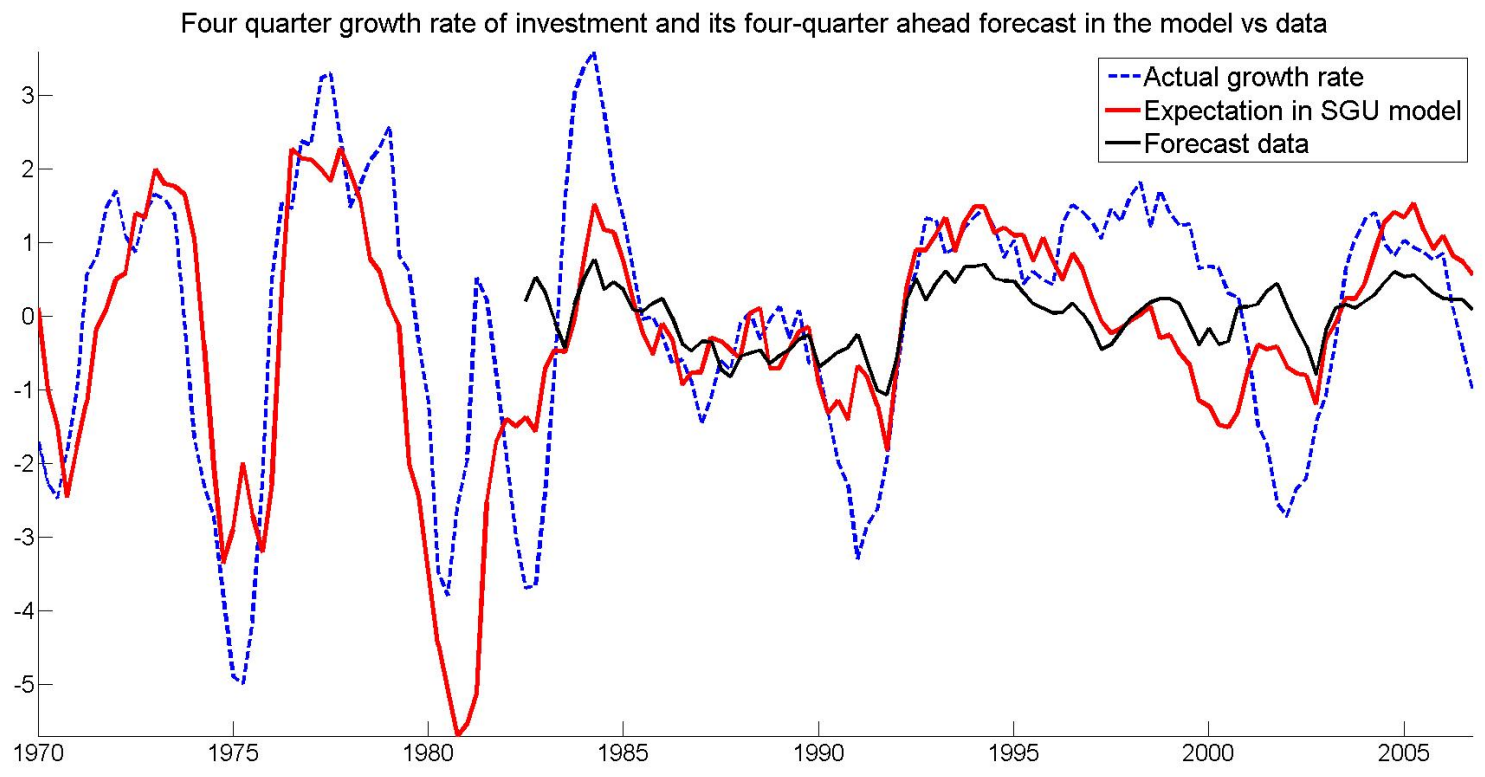

Figure A.2: SPF four-quarter investment growth rate forecast a year in advance and model-implied investment growth rate when estimated with data on expectations of output. 


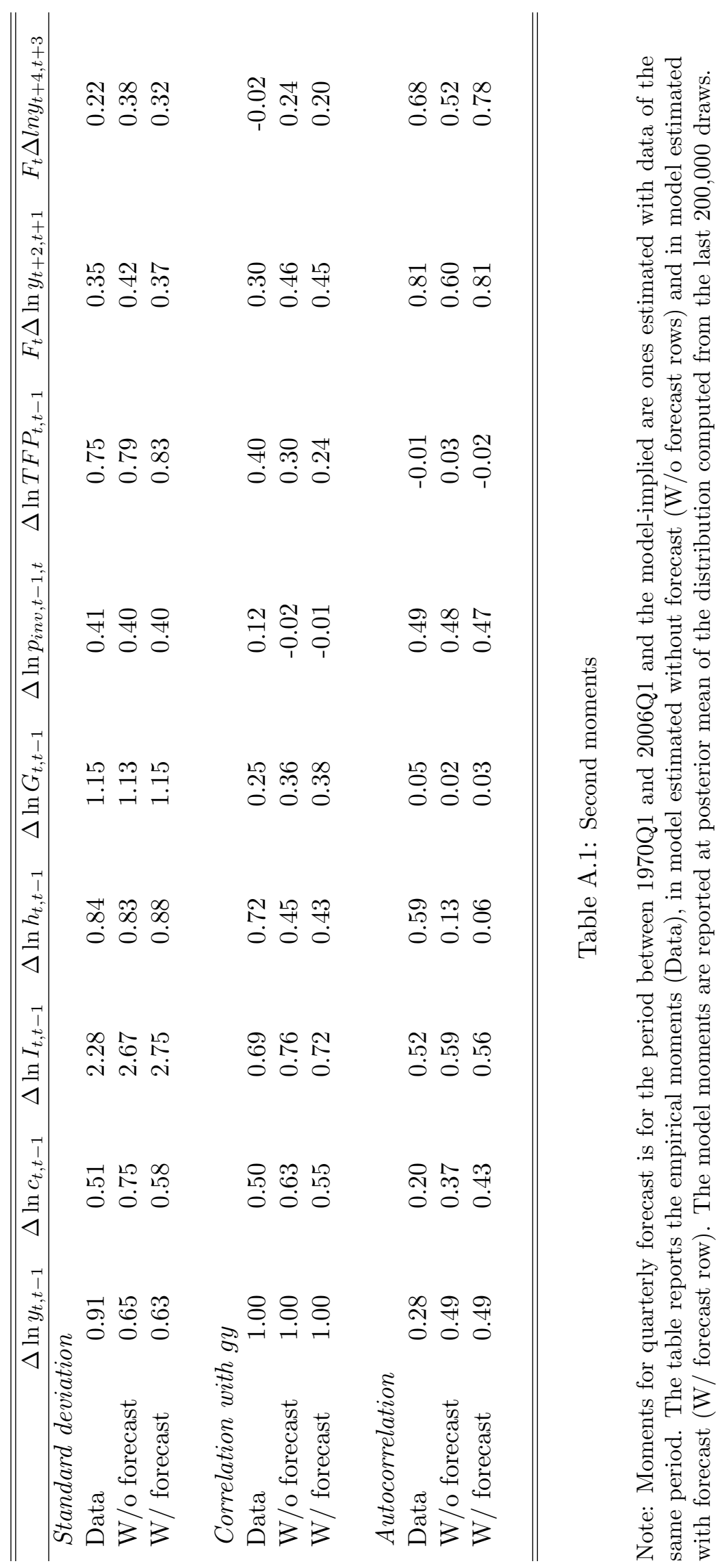




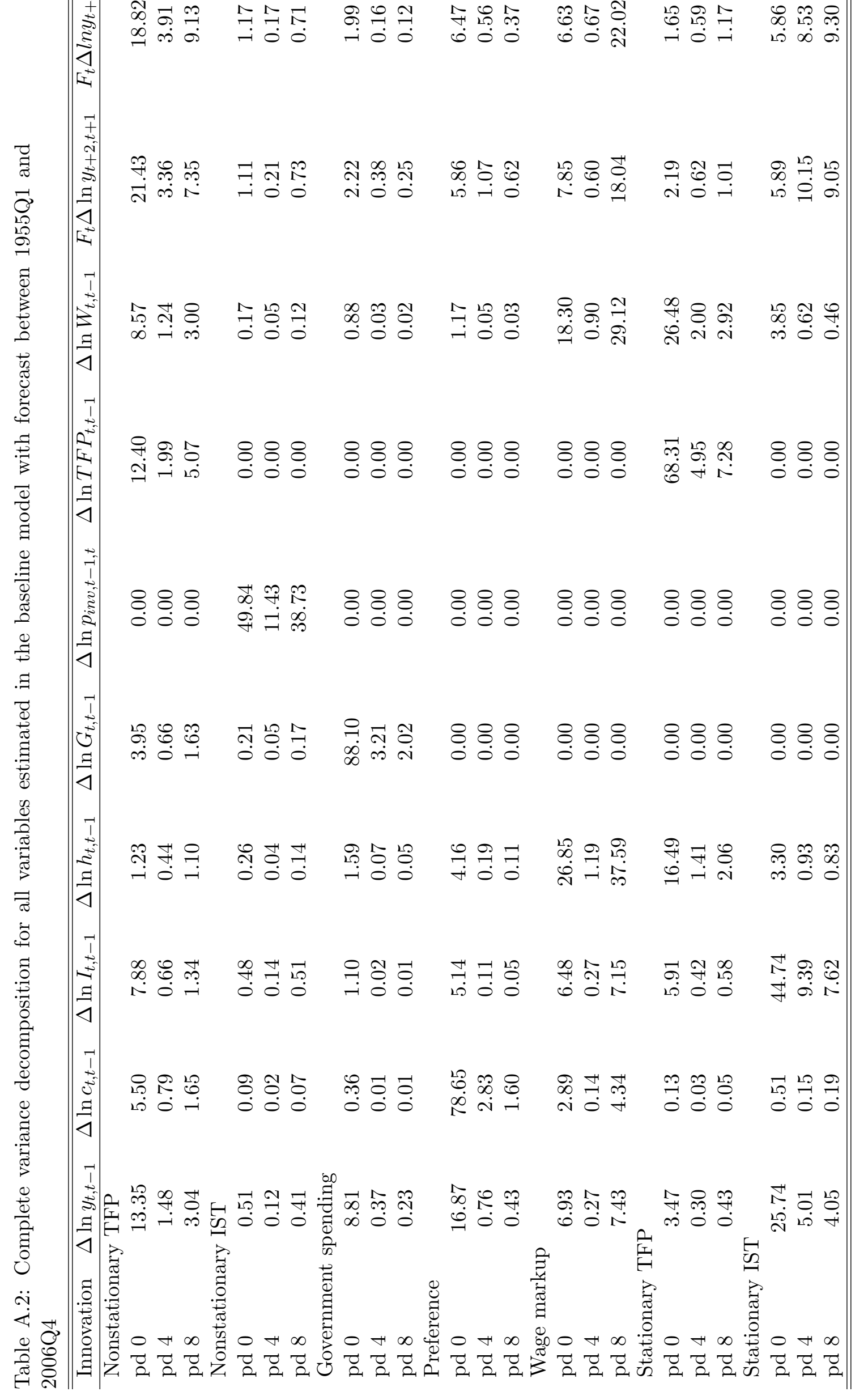




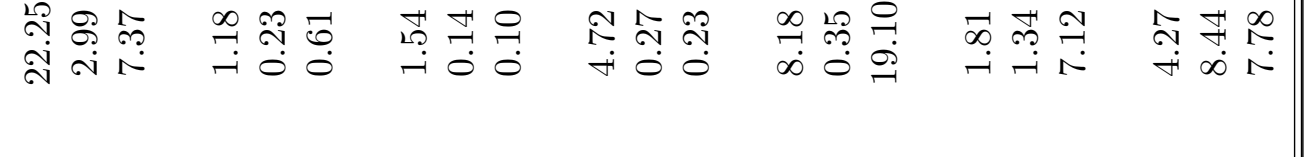

8

索$$
\text { 量 }
$$$$
\text { ฮี }
$$$$
\text { ฮ }
$$$$
\text { 돈 }
$$$$
\text { ग्ठ }
$$$$
\text { g్ }
$$$$
\stackrel{0}{+}
$$$$
\nexists
$$$$
\text { . }
$$

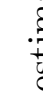$$
\frac{\pi}{2}
$$$$
\text { 蕓 }
$$$$
\text { శี }
$$$$
5
$$

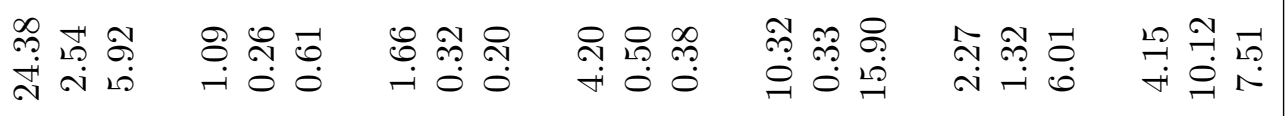

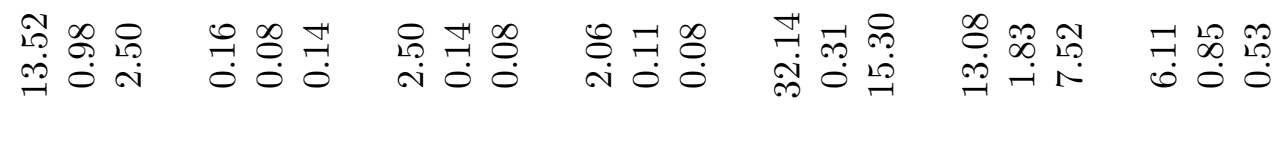

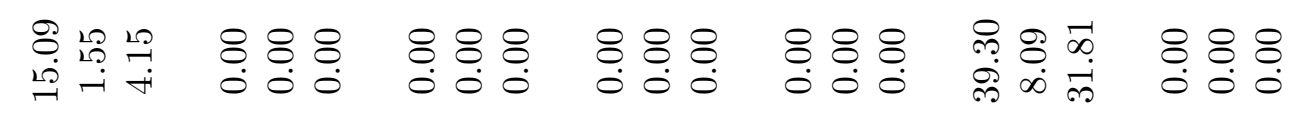

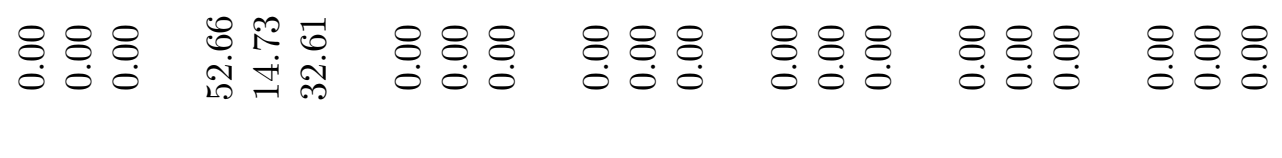

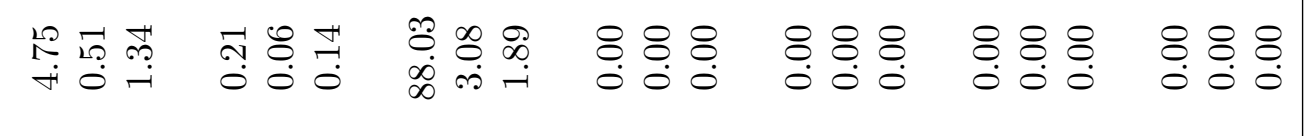

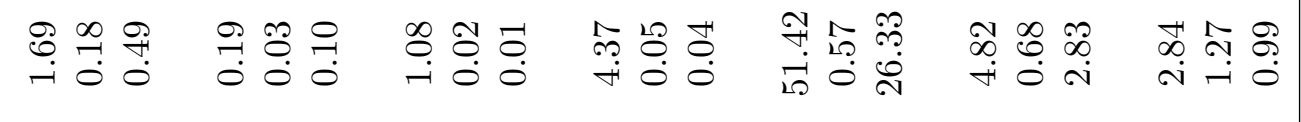

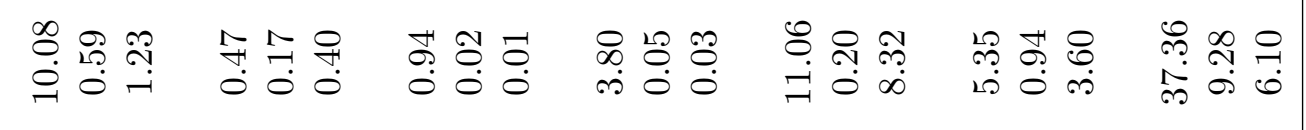

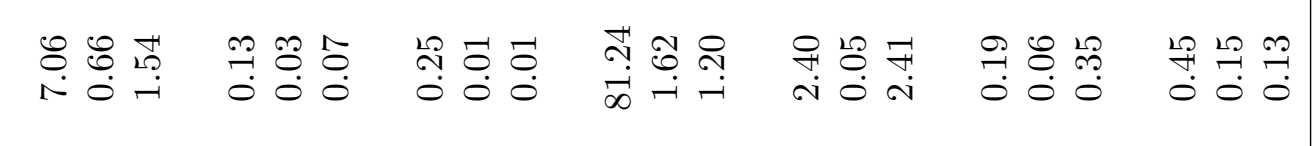
용

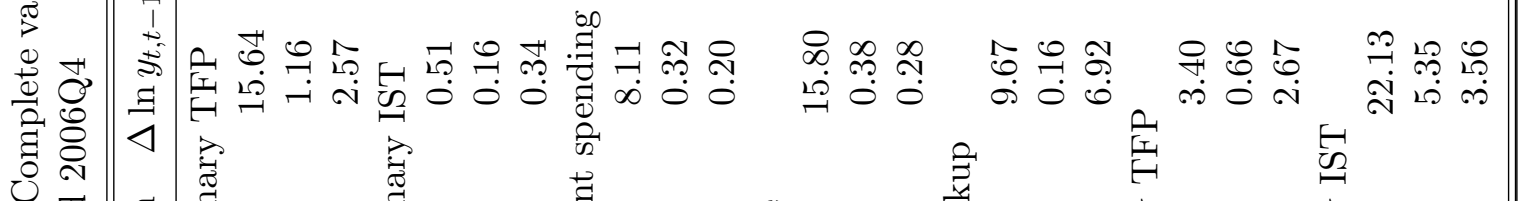

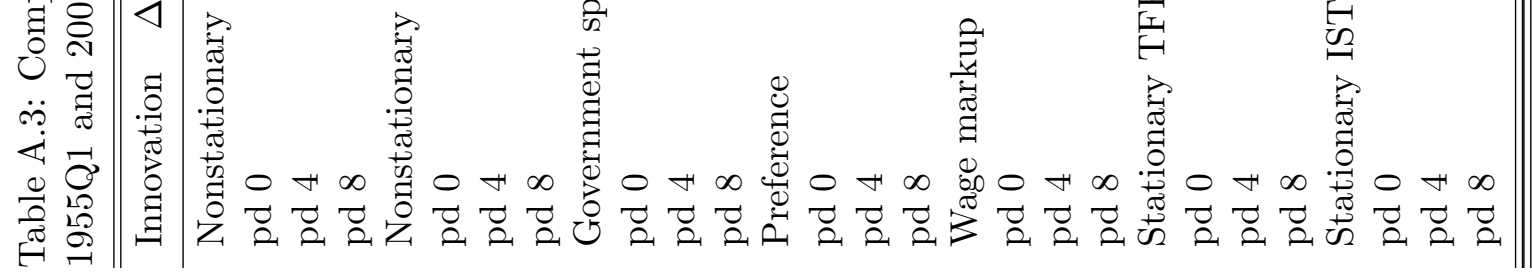




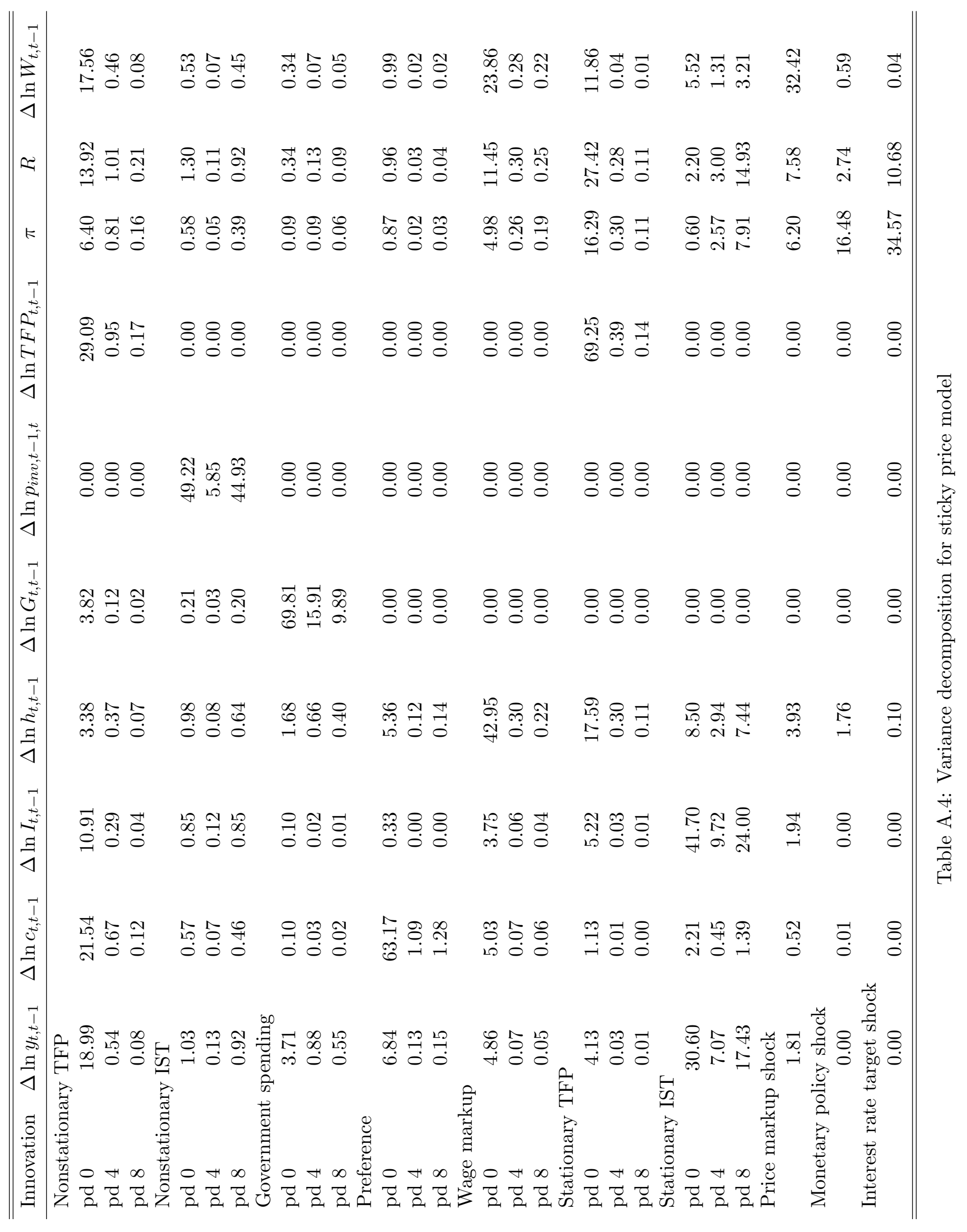




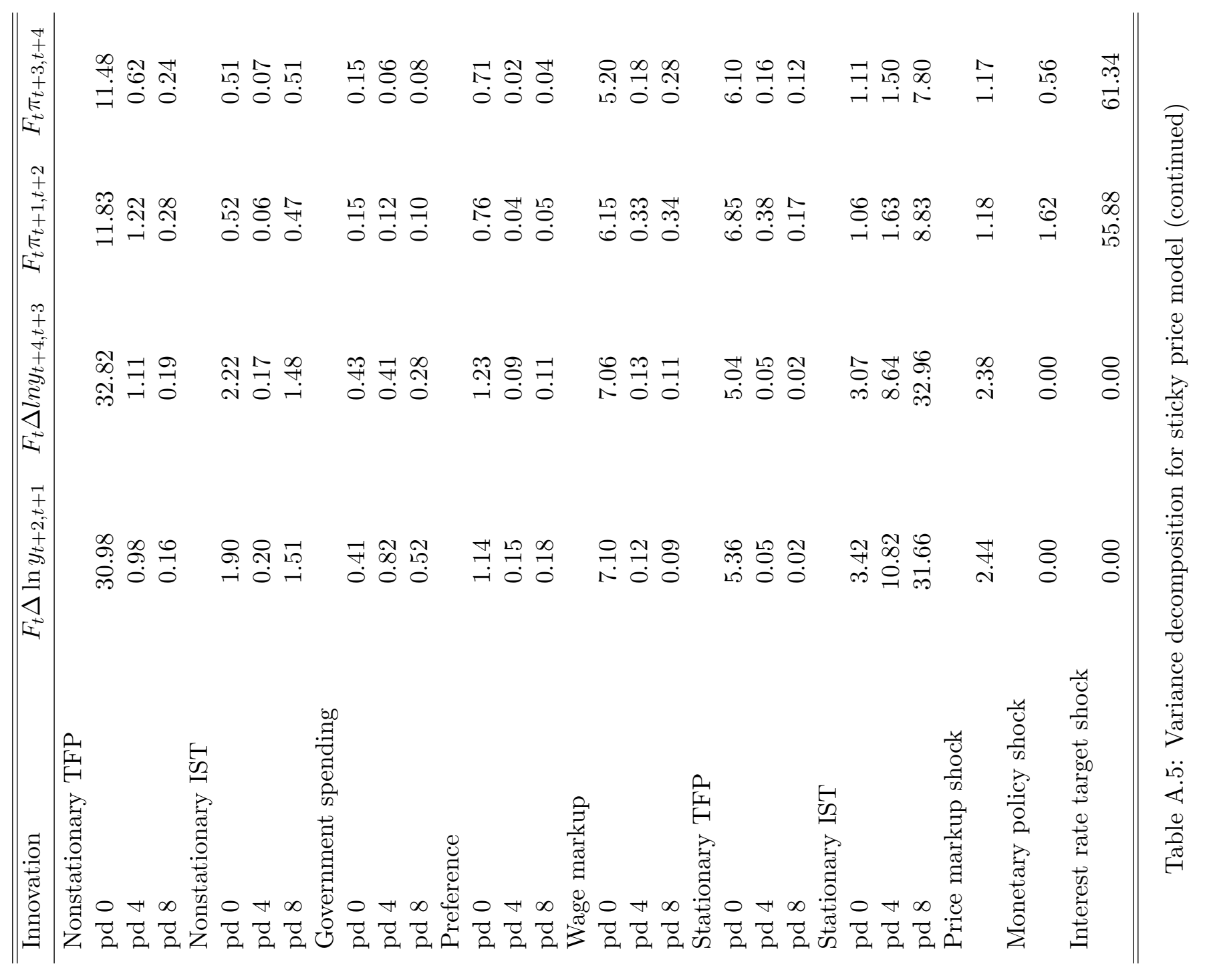

